\title{
A review of systems modelling for sustainability
}

\author{
Enayat A. Moallemi ${ }^{1,2,}$, Edoardo Bertone ${ }^{3,4,5 \dagger}$, Sibel Eker ${ }^{6, \dagger}$, Lei Gao ${ }^{7, \dagger}$, Katrina Szetey ${ }^{1, \dagger}$, Nick \\ Taylor $^{1, \dagger}$, Brett A. Bryan ${ }^{1, \S}$
}

${ }^{1}$ Centre for Integrative Ecology, School of Life and Environmental Sciences, Deakin University, Melbourne, Australia.

${ }^{2}$ Monash Sustainable Development Institute, Monash University, Melbourne, Australia.

${ }^{3}$ School of Engineering and Built Environment, Griffith University, Gold Coast, Australia.

${ }^{4}$ Cities Research Institute, Griffith University, Southport, Australia.

${ }^{5}$ Australian Rivers Institute, Griffith University, Nathan, Australia.

${ }^{6}$ International Institute for Applied Systems Analysis, Laxenburg, Austria.

${ }^{7}$ The Commonwealth Scientific and Industrial Research Organisation (CSIRO), Waite Campus, Australia.

* Corresponding author: Enayat A. Moallemi (e.moallemi@deakin.edu.au)

†These authors contributed equality and their names are ordered alphabetically.

$\S$ This author directed the project of which this study is a part.

\section{Abstract}

The 17 sustainable development goals (SDGs) represent a holistic and ambitious agenda for transforming the world towards societal well-being, economic prosperity, and environmental protection. Achieving the SDGs is, however, challenged by the performance of interconnected sectors and the complexity of their interactions which drive non-linear system responses, tipping points, and spillover effects in progress towards sustainability. Systems modelling, as an integrated way of thinking about and modelling multisectoral dynamics, can help explain how feedback interactions within and among different sectors can lead to broader system transformation and progress towards the SDGs. Here, we review how system dynamics, as one of prominent systems modelling approaches, can inform and contribute to sustainability research and implementation, framed by the SDGs. We systematically analyse 357 system dynamics studies undertaken at the local scale (e.g., communities, cities), published between 2015 (i.e., inception of the SDGs) and 2020. We analyse the studies to illuminate strengths and limitations in four key areas: diversity of scope; interdisciplinarity of the approaches; the role of stakeholder participation; and the analysis of SDG interactions. We assess strengths and limitations of the reviewed literature, and propose related research priorities in four areas: better consideration of societal aspects of sustainable development in modelling efforts; integrating with new interdisciplinary methods; improving genuine stakeholder engagement; a more in-depth analysis of feedback interactions underlaying the SDGs (i.e., synergies and trade-offs). The review provides a comprehensive knowledge base of existing works that can guide future applications and set a new research agenda for filling existing gaps in the application of systems modelling to sustainability.

Keywords: Sustainability; systems thinking; systems modelling; SDGs; review.

This manuscript is a preprint. The manuscript's status is currently 'submitted' for editorial assessment and a peer-review process. It has yet to be accepted for publication. Subsequent versions of this manuscript may have slightly different content. If accepted, the final version of this manuscript will be available via the 'Peerreviewed Publication DOI' link. Please feel free to contact the corresponding author; we welcome feedback. 


\section{Introduction}

The United Nations 2030 Agenda for Sustainable Development, commonly known as the SDGs, outlines 17 goals and 169 targets about economic development, social inclusion, and environmental sustainability (1). Since its adoption in 2015, the SDGs have been used across international, national, and local scales to set out development priorities and guide funding and policy interventions for their achievements (2). With the increasing adoption of the SDGs, the use of systems models has been also rapidly growing in support of planning for sustainability. Systems models are often used to better deal with the complexity and uncertainty inherent in understanding the long-term progress towards interacting goals and their synergies and trade-offs (3). Several specific modelling approaches, such as input-output analysis (4), computational general equilibrium (5), system dynamics (6), and agent-based modelling (7), as well as broader model-based paradigms such as integrated assessment modelling (8), transitions modelling (9), and exploratory modelling (10-12), have been used to systematically analyse sustainability in various ways.

Among past systems modelling efforts (13), system dynamics has been used historically for modelling complex feedback interactions, analysing interlinkages between sectors, and understanding non-linearities, radical change, tipping points, with many applications in the broader sustainability context $(14,15)$ as well as those directly related to the SDGs $(16,17)$. System dynamics has co-evolved with sustainability research over the past 50 years (18), starting in the early 1970s with Jay Forrester's World Model(s) for the Club of Rome (19). This model underpinned the seminal work of The Limits to Growth (20) which analysed global dynamics and projected the collapse of the socio-technological-natural system by the mid- $21^{\text {st }}$ century. Since then, the codevelopment of system dynamics and sustainability research has continued within different sectors including energy and environment (21), climate change (22, 23), and socio-cultural systems (e.g., poverty), within the broader context of sustainability $(24,25)$. Following the adoption of the UN Agenda 2030 in 2015, modelling sustainability with system dynamics gained momentum with a stronger tie to the SDGs. This included a range of sector-specific models related to individual SDGs (e.g., energy, water), nexus models that analyse interactions of multiple sectors and inform multiple SDGs (e.g., water-food-energy (26)), and integrated assessment models that capture socioeconomic processes with the Earth system dynamics and provide a systemic view of SDG interactions with their complex synergies and trade-offs $(14-17,25)$.

Current system dynamics studies of sustainability are diverse in scope, scale, model feedback structure, and their supporting analytical methods, leading to notable differences in their contribution to the field. A few seminal works have provided an overview of system dynamics as a general tool for learning about complex system behaviours $(27,28)$, and some studies have reviewed system dynamics in specific sectoral or disciplinary domains (e.g., transportation (29), supply chain (30), and water and hydrology (31)). Despite this progress, no study has reviewed and mapped the potential contributions of this diverse literature to understanding and informing sustainability as an indivisible whole with its broad sectoral and disciplinary span. Moreover, although sustainability has been always part of the system dynamics portfolio, the specific focus on the SDGs is still relatively a niche area. Given that sustainability research is at a stage where it has need for expansion and integration with other areas for better understanding the SDG complexities (32), a review of related systemic tools and applications across disciplines is timely and can be a point of reference. Such a review can bridge different research communities in sustainability and related fields to further develop and adopt systemic tools that are more effective for understanding the dynamics and interactions underlaying the SDGs. 
Here, we map and evaluate the key characteristics of system dynamics in support of planning for sustainability, framed by the SDGs, through a systematic literature review (Section 2). We critically analyse what system dynamics means for sustainability research and implementation and what the emerging research around the SDGs could potentially learn and benefit from systems thinking tools and concepts. First, this leads us to give due attention to the state-of-the-art of system dynamics modelling for sustainability with the explicit aim of evaluating their contributions for the SDGs (Section 3). Second, it also leads us to identify the current gaps in the connection of system dynamics and SDG research areas and to look forward to approaches that are currently not part of the standard toolkit of these areas, but their use in the future can push the research boundaries and bridge the two scientific communities (Section 4).

We analyse the state-of-the-art literature and investigate what avenues could be pursued in the future in four areas (Sections 3 and 4): the diversity of scope (i.e., the heterogenicity of context and analytical objective); interdisciplinary approach (i.e., methods from other areas used to support the analysis); the role of stakeholder participation (i.e., collaborative approach, timing of collaboration, the type of stakeholder groups involved); the analysis of interactions (i.e., SDGs studied together as a system). The review of the state-of-the-art and the analysis of related future priorities in these four areas provide a knowledge base of tools and applications that can promote further development of similar analytical methods aligned with the shared sustainability ambition under the 2030 SDG Agenda.

In our review and analysis, we focus on sustainability at a local scale, namely in relation to communities, small-scale businesses, cities, states or provinces, and sub-national regions. The choice of local scale is prominent given that SDG progress is highly dependent on knowing and managing the changes on the ground (33). Highly nuanced socioeconomic conditions and capacities and the diversity of stakeholder interests necessitate bottom-up initiatives that can be tailored to specific local characteristics (34). Bottom-up, grassroots efforts can be an opportunity to address place-based needs and priorities while also recognising the interlinkages with sustainability aspirations at higher scales. These give a crucial relevance to the local scale in the study of SDGs as a context where both impacts and initiators are on the ground.

\section{Methods}

We undertook a systematic review consistent with the Preferred Reporting Items for Systematic Reviews and Meta-Analyses (PRISMA) (35) via four main steps (Figure 1): (1) systematic literature search in Scopus; (2) screening of the search results for inclusion in review; (3) coding of included publications for data collection; (4) synthesis and analysis of collected data.

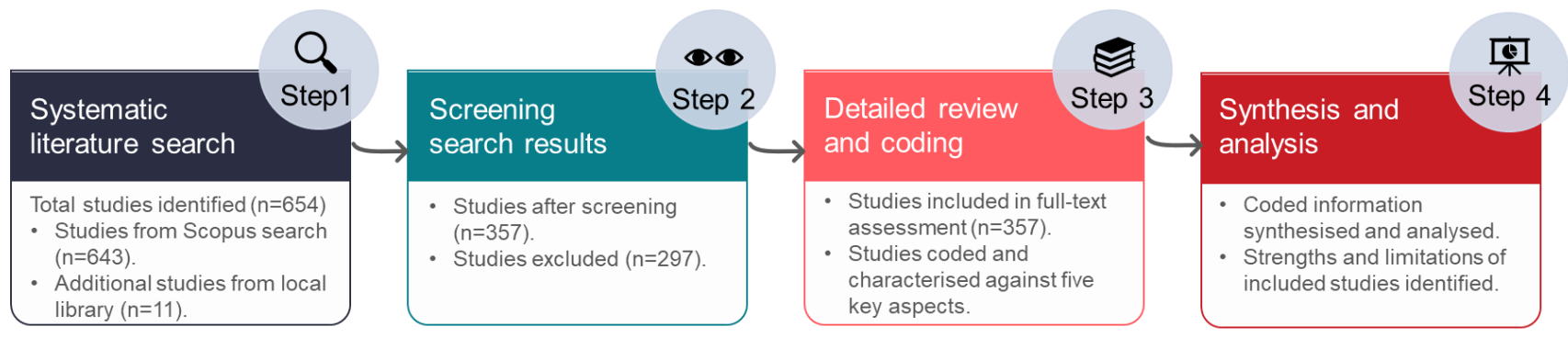

Figure 1. An overview of the steps in the systematic review. 


\subsection{Systematic literature search}

The first step aimed to systematically search for peer-reviewed articles in the Scopus database. Scopus was chosen because it covers a diverse range of sustainability and systems modelling journals related to the topic of this review. We started with a preliminary search to scope the diversity of keywords used in the related articles with a test search string: 'system dynamics' AND sustain* AND local $^{*}$. This initial scoping in conjunction with our knowledge of the literature iteratively developed the final search string constructed by three keyword components:

- The first component captured studies which used system dynamics. We used 'system dynamics' as one keyword rather than 'system' or 'dynamics' independently which could refer to other meanings not necessarily related to the system dynamics approach.

- The second component was to include studies that are related to sustainability. Here, we used three keywords. The first was 'sustain*' to include articles with any combinations of sustainability, sustainable development, and sustainable development goals. The other two were 'environ"' and 'ecolog*' to include studies that used environment or ecology as the integral components of (and sometimes interchangeably with) sustainability. The current selected keywords were informed by the scope of this review (i.e., specific to sustainability) and aimed to return a manageable number of papers rather than being too restrictive. We did not use 'SDG' as an independent keyword to minimise the exclusion of possible relevant system dynamics applications which contributed to various sustainability aspects (i.e., food, population, energy) so far but without mentioning the term SDG specifically. Even slightly expanding these keywords (e.g., 'health', 'energy') could return thousands of additional articles. However, we did not include these keywords as separate search terms as we only aimed for those system dynamics studies which were discussing sectoral issues in a sustainable development or sustainability context rather than articles related to general issues in healthcare, fossil fuels, or the electricity market. The significantly higher number of articles from further expanding the keywords used would also limit the ability to undertake a detailed review in the next steps. While we acknowledge that our choice of keywords could come at the expense of excluding some potentially relevant system dynamics articles with similar applications (e.g., in health or energy which might not mention 'sustain*' in their title, abstract, or keywords), this helped to limit the articles to a manageable number for review with limited irrelevancies.

- The third component was to capture the diversity of local scale studies. We used five keywords of 'local"', 'rural"', 'cit"', 'urban*', 'region*' to reflect different sub-national scales.

A second reviewer independently evaluated the composition of keywords to maximise the coverage of relevant articles and limit the inclusion of irrelevant articles. Using the selected keywords, we constructed the following search string with a time span from the beginning of 2015 (i.e., SDGs inception) to (mid-) 2020 (i.e., when this review was conducted):

- $\quad$ TITLE-ABS-KEY(“System Dynamics” AND (sustain* OR ecolog* OR environment ${ }^{\star}$ ) AND (local* OR rural ${ }^{\star}$ OR cit $^{\star}$ OR urban* OR region*)); LANGUAGES: (English) AND DOCUMENT TYPES: (article, review); SOURCE TYPE: (Journal); TIMESPAN: 2015-2020.

We excluded irrelevant subjects (e.g., neuroscience, physics and astronomy, biochemistry, genetics, and molecular biology) from our search results. This resulted in 643 total articles (without duplicates). In addition to the results of the search string, we also added 11 other relevant articles 
from our local library which did not appear in the search results with the selected keywords.

Together, they formed 654 potential articles (Data S1) to be assessed for relevance in the next step.

\subsection{Screening search results}

The second step involved screening collected studies for their relevance. We firstly read each study's title, abstract, and keywords in accordance with the PRISMA approach for systematic reviews. In the screening process, we excluded studies in our search results related to national or global scales which were incorrectly captured, those not using the system dynamics approach, those with the keyword 'sustain*' or "ecology* which had no topic relevance (e.g., 'sustainable' state of atoms in nuclear physics, 'sustainable' human body synthesis in biology), and those articles with no full text online access. As a result, the search results were narrowed down to those studies directly related to system dynamics for sustainability at the local scale. A second reviewer randomly checked around $10 \%$ of studies considered eligible and those ineligible in the first iteration. In total, 297 articles were deemed irrelevant, resulting in a final total of 357 articles (Data S2) for coding via a detailed assessment.

\subsection{Detailed review and coding}

In addition to bibliometric information (i.e., author, title, year, journal) of each study, we also collected complementary information by reviewing the abstract and full text of the final articles and coding them against four key areas (Data S2).

\subsubsection{Diversity of scope}

20 We represented the diversity of scope in collected articles in terms of: (a) the relevant SDGs that each article contributed to; (b) the geographical location of their case study (either as their main focus or as an illustrative example for method development); (c) the scale indicating what 'local' represented in each article (i.e., community/business, city/urban, state/province, sub-national regions); (d) the analytical objective (i.e., case-specific, methodological, review) from the use of system dynamics to better understand the nature and the type of questions answered and the way the results were interpreted within each context.

In terms of the analytical objective, we considered an article as case-specific when the primary focus was on addressing a sustainability problem/question, and system dynamics was used to inform the (real-world or hypothetical) application. These studies often included case-based models for developing contextualised insights for a specific problem. We considered an article as methodological when the primary focus was innovation in method and technique (e.g., to improve a model or develop a conceptual framework), and any case studies were used only as an illustrative example or proof of concept for the new methods. In contrast to case-specific, this analytical objective focused on generic insight development and adoption of a high-level of abstraction which remained independent from case studies and only made loose links to empirical data. We considered an article as a review if the primary focus was a comparative study of multiple methods, models, applications in relation to sustainability. In most cases during the detailed review, it was possible to associate a study to multiple objectives, but we only considered one of them as the primary objective based on our judgement.

\subsubsection{Interdisciplinary approach}

As a research method, system dynamics has been used across disciplines, from social, to physical, to natural sciences. To provide an overview of the intellectual contour of contributions from various disciplines, we initially specified the primary disciplinary lens from which the studies applied system 
dynamics in a local sustainability problem. Subsequently, within each discipline, we specified interdisciplinary methods used in support of system dynamics to highlight potentials for bridging between scientific communities. We also specified the scientific approach (i.e., qualitative or quantitative) used to apply system dynamics. An approach was deemed qualitative when the study's primary focus was on conceptualisation based on systems thinking, and quantitative when the study primarily relied on generation and analysis of quantitative data through simulation modelling. Anything in between was considered semi-qualitative (or equally semi-quantitative). We acknowledge that in some cases, there was no clear-cut boundary between qualitative and quantitative approach in the paper, and the coding was subjective to the authors' judgement about which approach dominates each article.

\subsubsection{Stakeholder participation}

Given the increasing role of stakeholders in co-developing models for sustainability (36-38), we specified the type and extent of stakeholder participation in the reviewed studies. We initially specified collaboration with stakeholders to determine whether the study was participatory or nonparticipatory. We considered a study participatory when stakeholder interactions were considered in developing concepts/models, validating generated results, and/or communicating insights. We considered a study as non-participatory when the analysis relied on models and data from documents with limited or no direct stakeholder input. If a study was deemed participatory, we then specified the collaborative approach to indicate whether participation was front-end (i.e., engaging with stakeholders from early stages of problem definition and model development), back-end (i.e., engaging towards the end in validation of results and communication of outcomes), or both. We also specified stakeholders involved to identify the type of stakeholder groups, including community members (i.e., general public), sectoral practitioners (e.g., technical experts who are often involved on the on-ground management), decision-makers (i.e., responsible for policy-making, budget allocation, etc.), and researchers, who informed the analysis.

\subsubsection{Interaction analysis}

No individual SDG on its own is sufficient, and the whole SDGs as a system of synergistic reinforcements (39) is necessary for successfully implementing the 2030 Agenda. This signifies the importance of interactions and dependencies among the SDGs. We specified whether each study could be related to a single or multiple SDGs (and which SDGs were studied together) to highlight to what extent past system dynamics research in local sustainability has covered, directly or indirectly, the interactions between various societal, economic, and environmental sustainability goals. While we identified interactions, we did not analyse whether the study was related to synergies or trade-offs (i.e., positive or negative interactions, respectively) given that at least some insights related to both can be often identified when a study discusses interactions.

\subsection{Synthesis and analysis}

We synthesised the coded information across all included studies (Data S2) and provided an analytical summary from strengths and limitations of the current literature in relation to the four analysed areas listed in Section 2.3.

\section{Results}

This section provides an overview of what has been done in system dynamics modelling for sustainability, both in the general sense of the applications out there and in the sense of topical areas, objectives, case studies, techniques, and engagement approaches. The emphasis is on showing the 
diversity of the field and evaluating the contributions (i.e., areas of strengths and limitations), framed by the SDGs and at a local scale (Section 2).

\subsection{Diversity of scope}

In terms of the topical domain, system dynamics has been applied to local sustainability in the context of different SDGs, but the main focus has so far been limited to only a few goals (Figure 2a). From the 357 reviewed studies, the highest numbers were related to applications in clean water and sanitation (SDG6), sustainable cities and communities (SDG11), and industry, innovation, and infrastructure (SDG9) (24\%, $24 \%$, and $18 \%$ of studies, respectively). To illustrate, system dynamics applications related to SDG6 covered a diversity of topics such as urban water supply and waste water management $(40,41)$, drought and water security in dry regions (42), and irrigation and water management for food production and agriculture (43). Studies related to SDG11 spanned a wide range of topics too, including sustainable transportation and emissions reduction in cities (44), building and infrastructure improvement (45), and eco-cities and sustainable urban development (46), amongst others. Studies related to SDG9 discussed topics such as sustainable development of specific industries and industrial regions (47) and improving public infrastructure (e.g., natural disaster management (48), logistics and transportation (49)). The use of system dynamics, however, has been limited in the case of other SDGs. For example, no article among the reviewed studies focuses on local challenges in gender equality (SDG5), and there are only a few works on reduced inequalities (SDG10), poverty reduction (SDG1), and quality education (SDG4) at the local scale (see Section 4.1 for discussion).

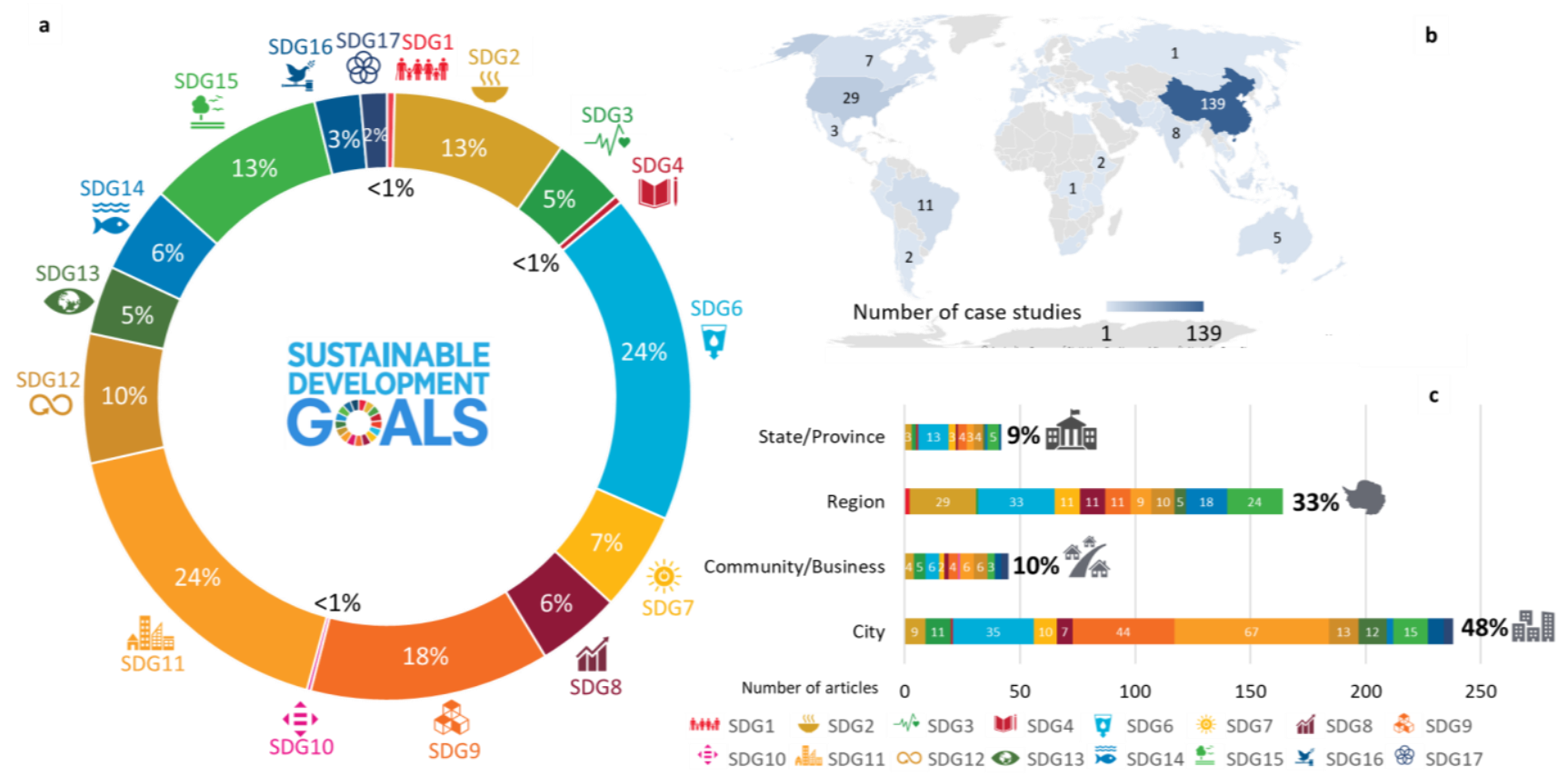

Figure 2. The diversity of scope in terms of (a) topical domain, (b) geographical location, (c) spatial scale. In (a), a study can cover multiple SDGs, hence the fractions in the pie chart add up to more than $100 \%$, and the studies covering multiple SDGs are discussed in Section 3.4. Numbers inside stacked bar chart (c) show the number of studies per SDG. Numbers not visible in (b) and (c) are for those categories with limited space for text annotation. SDG5 (gender equality) is excluded from (a) to (c) as there is no study in the review related to this goal. The SDG icons are the courtesy of the UN SDGs Communications materials.

In terms of the geographical location, case studies presented in the system dynamics papers reviewed were concentrated in a few developing countries whereas those in developed countries were less frequent and were also slightly more evenly distributed (Figure 2b). In both cases, only a few countries dominated the case studies related to each SDG (which could be due to the popularity 
of system dynamics as a field in their tertiary education system, and therefore a larger number of scientific papers). While there were common issues (e.g., sustainable food and agriculture in SDG2, sustainable cities and communities in SDG11) that were discussed frequently in both developed and developing countries, there were also some sustainability problems that were more popular in one compared to another. For example, issues related to health and well-being in SDG3 and partnership for the goals in SDG17 were less discussed overall and in developing countries in particular, compared to other goals (Data S2).

In terms of the spatial scale (Figure 2c), most studies focussed on cities (48\%) where the concentration of political power and capital tends to be, and where some of the most pressing local sustainability challenges, such as pollution (50), logistics, traffic, and mobility issues (51), and management of infrastructure projects (52), have a critical condition. Cities are also important in the study of local sustainability given their dense population and therefore their high vulnerability and security risks to natural and anthropogenic threats. Regions formed the second most common study scale (33\%), mostly dealing with the management of natural resources (48), amongst other topics (e.g., the development of industrial regions (53), cross-comparisons (or meta-analysis) between performance of multiple regional areas (54)). Rural or sub-urban communities, local businesses, and states (or provinces) were presented in case studies less frequently (each $\leq 10 \%$ ).

The results showed potential links between the scale and the SDG(s) of focus across the reviewed studies. To illustrate, studies related to SDGs 14 and 15 (i.e., life on land and life below water) were mainly discussed at the regional scale where the boundaries, drivers, and impacts of natural habitats change (e.g., forests, lakes, and wetlands) extend beyond a single city or a local community and can include large regions, sometimes even span multiple countries. On the other hand, SDGs 6 and 9 were discussed more frequently in applications at the city scale where issues such as storm and waste water management (55), and logistics and transportation (56) are often more relevant dimensions of sustainability.

Similar relationships were also observed between geographical location and study scale. Applications in developing countries focused on the city scale $(50 \%)$ more frequently compared to other scales (e.g., $30 \%$ on regional scale). One reason for this relationship is the growing population of cities in developing countries (e.g., $90 \%$ of global urban population increase has occurred in Asia 30 and Africa (57)) and their rising sustainability challenges such as pollution, traffic, and logistics. Conversely, sustainability issues among studies in developed countries were more evenly distributed between cities (45\%) and regions (42\%) where the management of natural resources and ecosystems is often a key focus. Another reason is that developed countries have historically provided better socioeconomic conditions, but had created large environmental and material footprints (e.g., increasing emissions and food waste) in their surrounding environment which need to be addressed for the successful implementation of the SDGs (39). While studies at the scale of local communities were limited in general across all geographies, those in developed countries still had a larger share $(11 \%)$ compared to those in developing countries $(8 \%)$. This can reflect the emergence of local communities as a niche area of application and that more bottom-up initiatives in achieving sustainability exist among developed countries (33).

With respect to the analytical objective, most of the reviewed studies (63\%) were classified as methodological improvement where the main focus was on model (or a conceptual framework) development, and the case study application was primarily a demonstration of the methods (Figure 3 ). These results reflected the diversity of models that existed in the system dynamics area and the fact that new models (both in terms of structure and parametrisation) were often being developed to 
suit a given problem (as opposed to other modelling domains where a handful of reference models are often applied across cases). One example of these studies was Liu et al. (58) where they focused on developing a specific decision support system to inform the impact of policy interventions on land-use change. Their primary contribution was methodological innovation via integrating multiple modelling paradigms (i.e., system dynamics, agent-based, cellular automata models). The popularity of method development was a common feature across studies related to most of the SDGs (e.g., $75 \%, 68 \%$, and $63 \%$ of studies related to SDG9 on industry, innovation, and infrastructure; SDG11 on sustainable cities and communities; and SDG6 on clean water and sanitation, respectively).

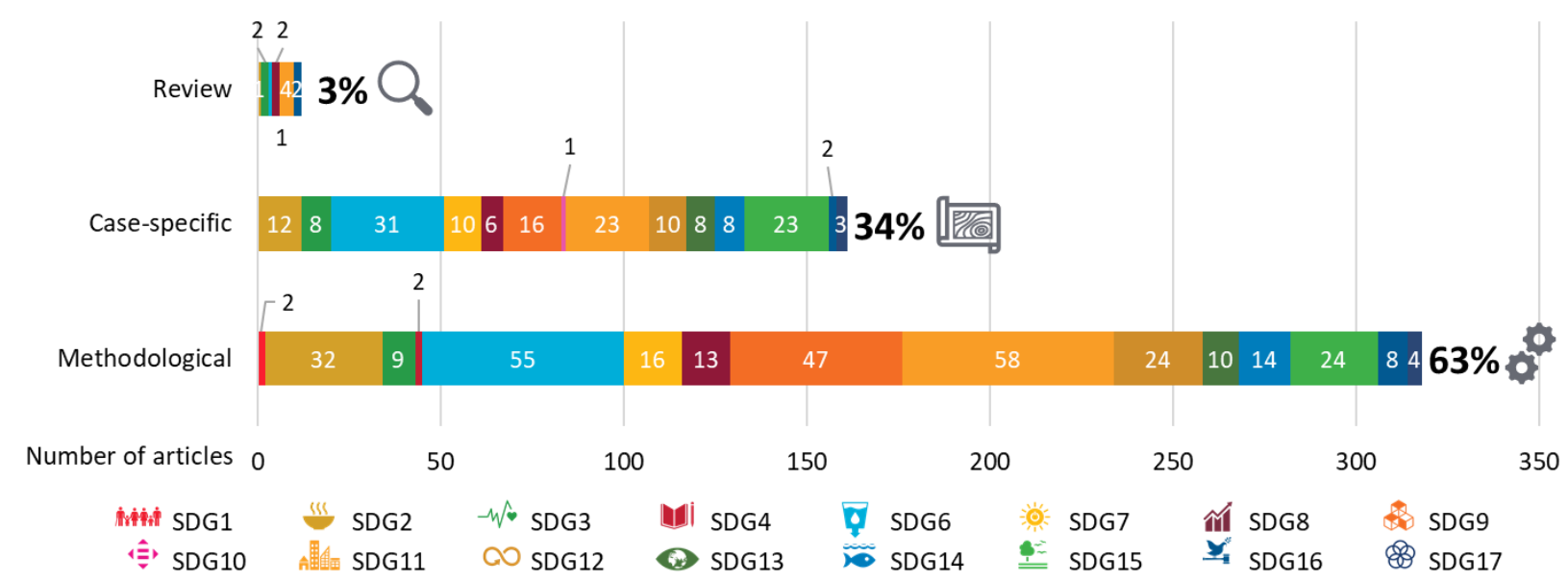

Figure 3. Analytical objective overview. SDG5 (gender equality) is excluded as there is no study in the review with a direct link to this goal.

$34 \%$ of the reviewed articles were classified as case-specific where an application in addressing a sustainability challenge was the primary aim of the study. Any model development was assumed to be used for answering related empirical questions. For example, (59) aimed to understand how large-scale changes affect dryland sustainability as an empirical research question. They used system dynamics as a tool to assess the interactions of various large-scale changes with dryland's endogenous sustainability drivers and to quantify their impacts. Among the SDGs with highest share of case-specific articles included SDG15 on life on land (49\% of related articles), SDG13 on climate action ( $44 \%$ of related articles), and SDG17 on partnerships for the goals ( $43 \%$ of related articles). Finally, $3 \%$ of the articles were classified as review where the aims were the evaluation of related studies about a specific sustainability issue (60), a comparison of methods for a certain class of local challenges (61), amongst others.

\subsection{Interdisciplinary approach}

An important feature of system dynamics is its extensive connections with other established fields. The results showed the study of local sustainability with system dynamics through the lens of a broad range of (sometimes overlapping) disciplinary areas associated with different SDGs (Figure $4 b)$. By frequency, these fields included sustainable development (32\%), water and hydrology $(18 \%)$, and agricultural studies (11\%), to less common areas such as climate change $(3 \%)$, transportation (4\%), and ecology (4\%). Despite association to a primary field, most of the reviewed studies were identified as interdisciplinary as they integrated a mix of methods across disciplines in support of system dynamics, or their applications lay at the intersection of multiple sectors (e.g., water resource management and aquatic ecology (62), energy and climate (63)). The integration of methods often aimed to support early modelling steps such as problem formulation and dynamic 
hypothesis development. For example, Walters and Javernick-Will (64) integrated system dynamics with social science techniques (e.g., survey, Delphi method) in a participatory process to specify factors affecting rural water services and its dynamics, to inform the modelling of feedback interactions. Integration sometimes aimed to enhance the model building process. An example was the integration of system dynamics with other modelling approaches such as agent-based modelling (65) or computational general equilibrium modelling (66) to better account for the heterogeneities in actors' behaviour and decision-making. Another example was the integration of system dynamics with Bayesian Networks (67) to effectively deal with missing data and uncertainty. Integration with other methods was also used for the analysis of the modelling results. An example for this type of integration was the use of scenario analysis for policy evaluation under alternative future conditions and for coping with uncertainties and risk assessment in model projections (68) (see Section 4.2 for discussion).

a

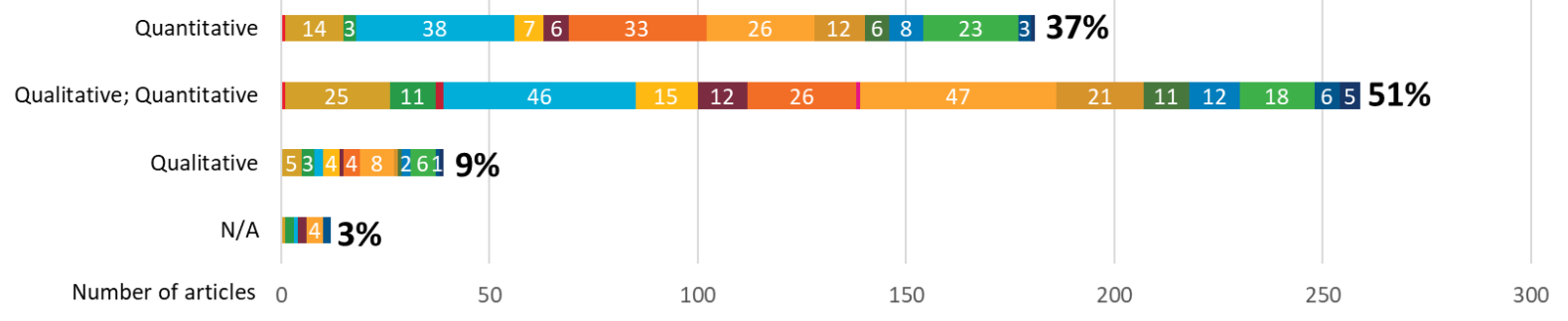

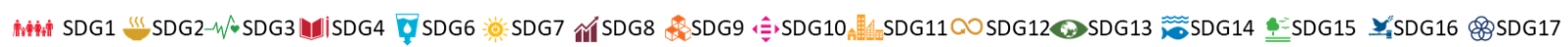

b

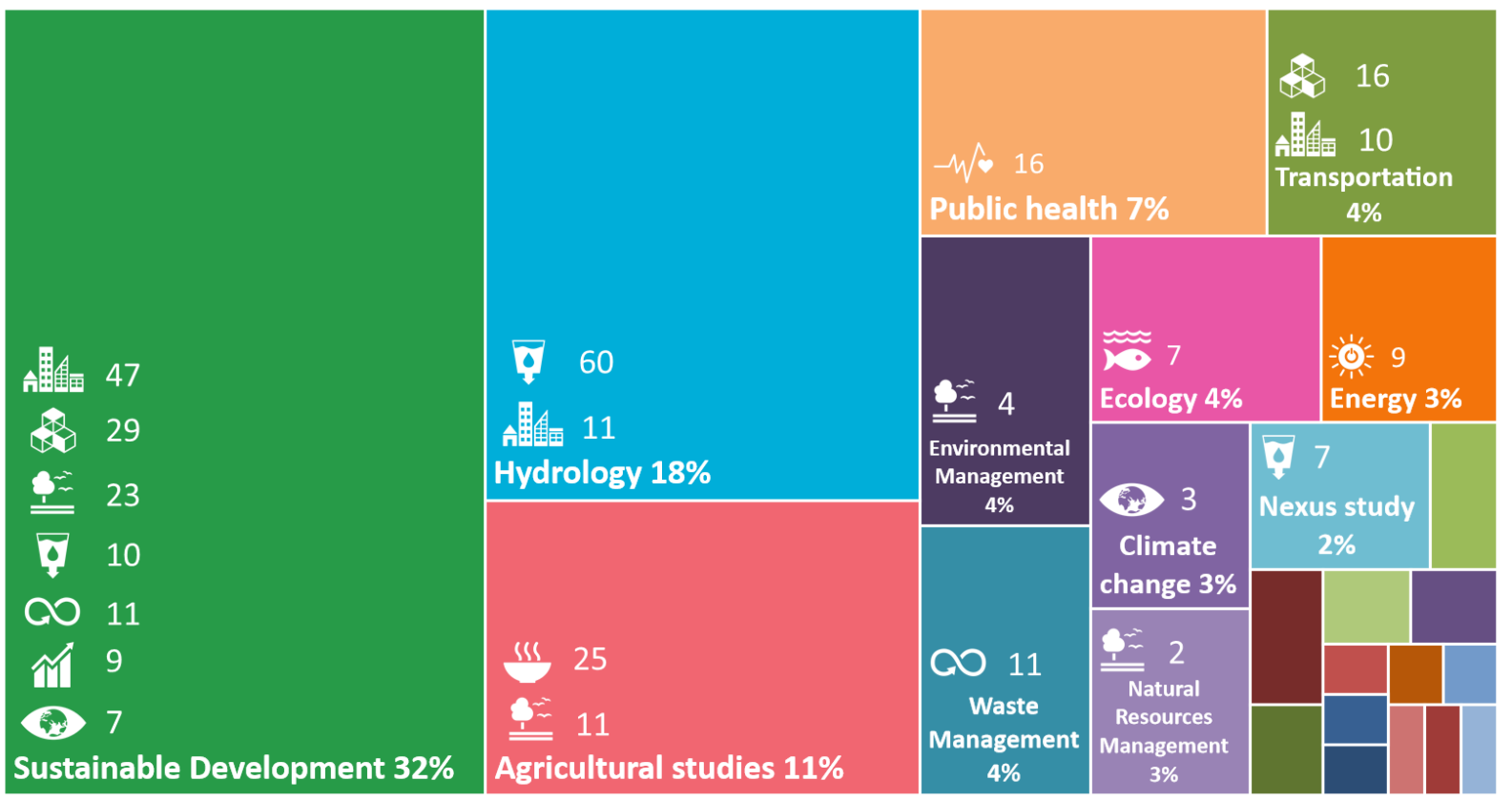

Figure 4. Overview of interdisciplinary approaches used in support of system dynamics. (a) is share of qualitative vs. quantitative approach and (b) is the disciplinary lens from which each study adopts system dynamics. N/A in (a) represents studies (i.e., review articles) where our definitions of qualitative and quantitative approach were not applicable. SDG5 (gender equality) is excluded from (a) as there is no study in the review with a direct link to this goal. Each tile in (b) represents a disciplinary area, and the listed icons inside each tile represent the SDGs discussed the most from that respective disciplinary lens. Numbers inside (a) and (b) show the number of studies per SDG. Numbers and labels not visible in (a) and (b) are for those categories with limited space for text annotation.

Both qualitative and quantitative methods were adopted (Figure 4a). However, the majority of the reviewed studies (51\%) adopted a mixed qualitative and quantitative approach. A common example of a mixed approach was when insights from a conceptual framework (e.g., cognitive causal loop diagram, scenario narratives) developed with stakeholders complemented and supported computer simulations and the quantification of system behaviour. $37 \%$ of the reviewed studies primarily 
adopted a quantitative approach. Exploring non-linear complex interactions (69) and analysing the effects of long-term uncertainties on system behaviour (70) were two examples of studies with a primarily quantitative approach. $9 \%$ of the studies also adopted a primary qualitative approach aiming, for example, at conceptualising system processes (71) or providing a detailed account of heterogeneities in system dynamics (72).

\subsection{Stakeholder participation}

Despite the potential benefits of engaging with stakeholders in support of modelling, only $28 \%$ of the reviewed articles was identified as participatory system dynamics studies (Figure 5a). The degree of participatory engagement also varied across the SDGs. For example, despite a limited number of articles, applications related to SDG4 on quality education, SDG10 on reduced inequalities, and SDG17 on partnerships for the goals had the highest share of participatory articles $(100 \%, 100 \%$, and $71 \%$, respectively). However, the majority of articles related to other SDGs, such as SDG13 on climate action, SDG9 on innovation and infrastructure, and SDG6 on clean water and sanitation had a limited share of participatory articles $(11 \%, 16 \%$, and 16\%, respectively) (see Section 4.3 for discussion).
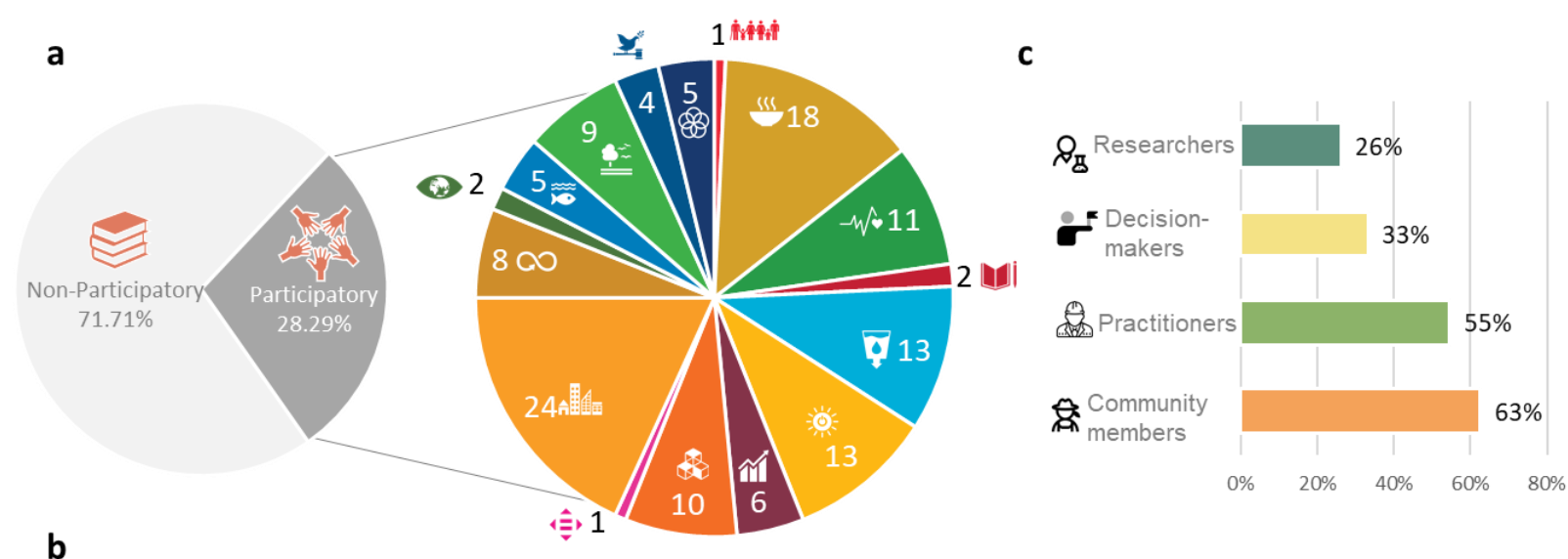

b

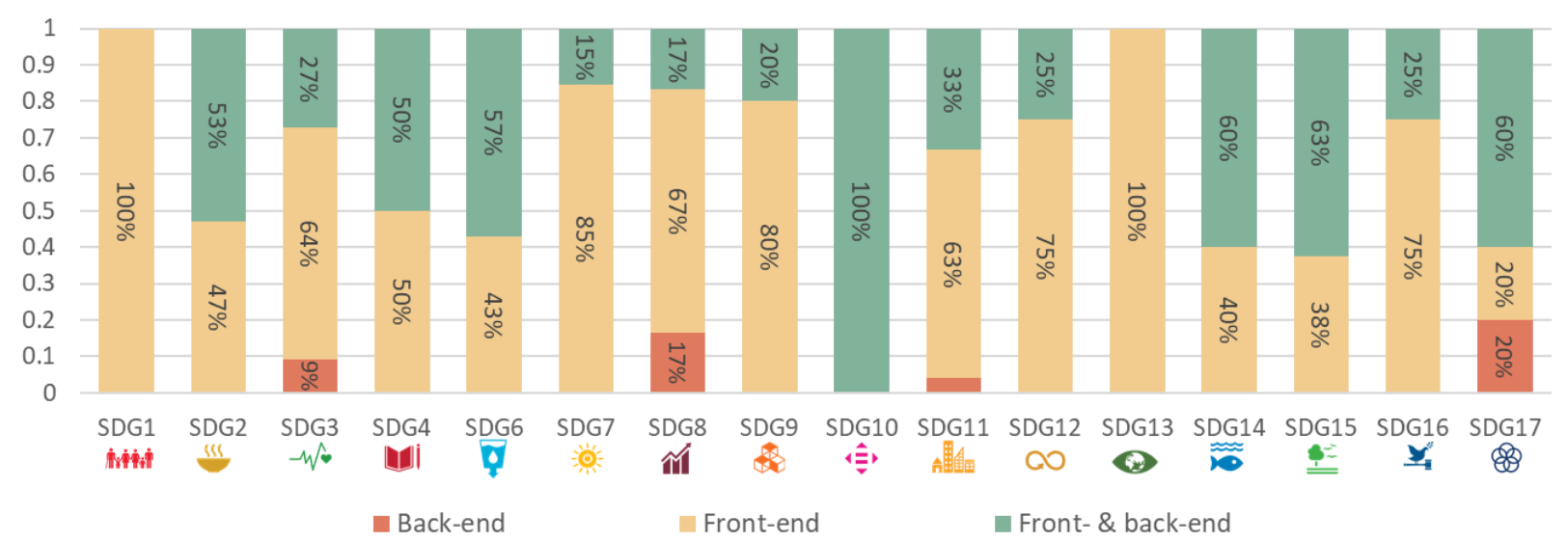

Figure 5. Overview of stakeholder participation. (a) shows share of participatory to non-participatory research across all included studies and in each SDG where the numbers represent the number of studies. (b) shows the timing of engagement across studies per each SDG. (c) shows to what extent different types of stakeholders were involved across the reviewed studies. See Section 2.3 for the definition of these stakeholder groups. A study can have multiple stakeholder groups involved, hence bars in (c) add up to more than $100 \%$.

Among participatory system dynamics modelling studies (Figure 5b), stakeholders mostly had frontend engagement (59\%) to inform problem definition and model development, for example, in demarcating the system boundary with inputs from the community (73) and co-developing a 
dynamics hypothesis with stakeholders to test and evaluate with models (74). $3 \%$ of the included studies were classified as back-end engagement in support of the validation of results and communication of outcomes with stakeholders. Stakeholder engagement in $38 \%$ of the included studies was identified as both front-end and back-end, for example to inform problem scoping and boundary setting during model development as well as to validate model results and ensure robust outcomes negotiated among participants towards the end of the project (75). There were also often multiple stakeholder groups involved in participatory system dynamics studies (Figure $5 \mathrm{c}$ ). Among stakeholders, community members formed the most common group $(63 \%)$, followed by practitioners (55\%), decision-makers (33\%), and researchers (26\%) (note that more than one group can be associated to each study). The involvement of different stakeholder groups, however, varied across the SDGs. For example, practitioners were the most common stakeholder group involved in SDGs 6, 9, and 13 (i.e., clean water and sanitation, innovation and infrastructure, and climate action) whereas community members were more engaged in SDGs 2, 3, and 4 (i.e., food and agriculture, well-being, and quality education).

\subsection{Interaction analysis}

System dynamics is the correct tool for understanding and explaining the co-development of systems underlaying different goals as an indivisible whole. From the included studies, 133 articles were associated with more than one SDG where they capture complex (positive or negative) interactions among social, economic, and environmental aspects of local sustainability (Figure 6). Among them, sustainable cities and communities (SDG11) had the largest share of studies considering interactions (59 studies). Cities and communities were a major part of the study of sustainability at the local scale, and therefore many of the collected studies were associated with SDG11, in addition to links to other goals. Notable interactions from sustainable cities and communities were with industry, innovation, and infrastructure (SDG9) (22 studies). The interactions between these two goals were through various targets. One example was via the city and community links to sustainable and resilient transportation and logistics and supply chain infrastructure with affordable and equitable access that supports economic development as well as human well-being (Target 9.1) (76). System dynamics research on cities and communities also substantially interacted with clean water and sanitation (SDG6) (14 studies) via targets under SDG6 such as access to safe and affordable drinking water (Target 6.1) (77), improving water quality and wastewater treatment (Target 6.3) (78), addressing water security and water scarcity (Target 6.4) (79), and integrated water resource management (Target 6.5) (63). Sustainable cities and communities had the third highest share of interactions with life on land (SDG15) (7 studies). Notable examples of these interactions were through sustainable management of land and urban afforestation $(80,81)$, conservation and restoration of freshwater ecosystems and urban wetlands (Target 15.1) (82), and the design of eco-friendly solutions to enhance urban living (46) (Targets 15.1 to 15.3 ).

Other prominent interactions were also observed in the results. The first interaction was between responsible consumption and production (SDG12) and decent work and economic growth (SDG8) (7 studies), for example, how sustainable tourism activities can create jobs while using natural resources efficiently $(83,84)$. The second interaction was between zero hunger (SDG2) and life below water (SDG14) (7 studies), for example, focusing on the management of commercial fishing with a balance between stock replacement and prices of fish to supply food (85). The third interaction was between clean water and sanitation (SDG6) and responsible consumption and production (SDG12) (6 studies), for example, looking at the management of reactive nitrogen flows from food production in wastewater systems (86)). Having a high number of studies focusing on each of these interactions was the result of similar (or closely related) targets under their respective 
SDGs. For instance, observed interactions between decent work and economic growth (SDG8) and responsible consumption and production (SDG12) were the result of two closely related targets under these goals, i.e., decouple economic growth from environmental degradation via 'resource efficiency in consumption and production' (Target 8.4) and 'achieve the sustainable management and efficient use of natural resources' (Target 12.2), respectively (see Section 4.4 for discussion).

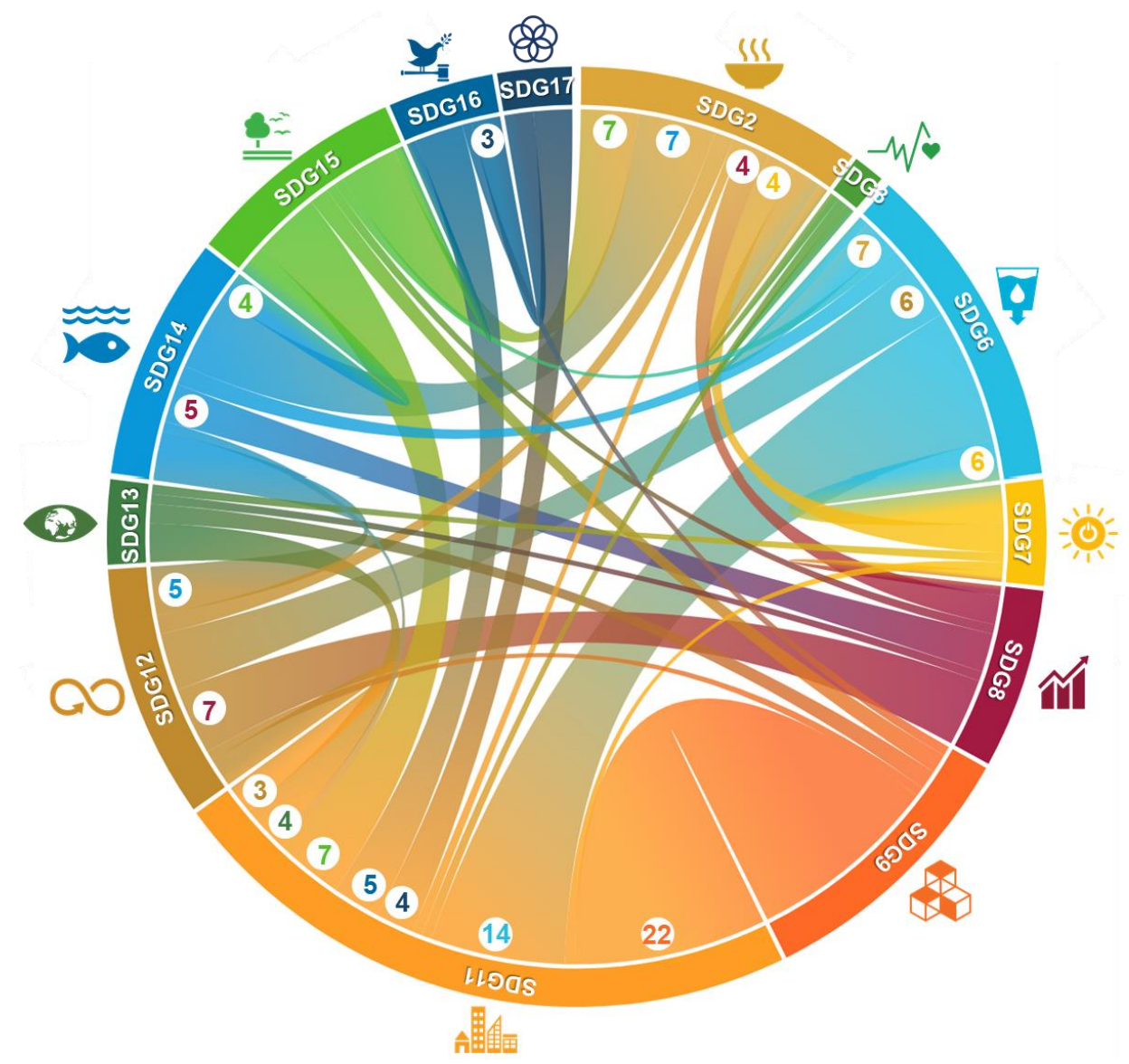

Figure 6. Overview of interactions between pairs of SDGs studied across the reviewed articles. Each SDG is represented by a fragment on the outside of the circle. Arcs drawn between each SDG represent interactions. The size of the arc is proportional to the number of studies, also annotated in small circles for major interactions. Annotated numbers are not repeated on both sides of each arc and are only on one side connected to the SDG with higher total interactions. SDG5 (gender equality) and SDG10 (reduce inequality) are excluded as no study in the included studies focused on interactions with these goals. The Chord diagram was developed by the Python-based Chord package (87).

\section{Discussion}

This section expands on the major gaps that were identified in Section 3 to show their implications for the SDG research and then discusses potential ways to address the gaps in the future, in each of the four areas of our review (Section 2.3). In discussing the gaps and future priorities, the emphasis is on highlighting the ways that system dynamics and SDG research communities can co-develop and learn from each other's key issues and capabilities and also from those capabilities of other related fields.

\subsection{Diversity of scope}

20 Despite the diversity of the reviewed articles in terms of their scope, system dynamics studies in relation to the societal challenges such as poverty (SDG1), quality education (SDG4), and inequality in its all forms (SDGs 5 and 10), have remained underdeveloped (Section 3.1). Societal problems in the reviewed studies were often modelled based on the 'average' properties of the (e.g., population, spatial, economic) systems with 'representative' indicators (e.g., standard gross domestic product per capita for modelling economy) and at a highly aggregated scale (e.g., general urban problems 
rather than issues among communities). This limited the modelling of the distributional effects and the disaggregation of progress across scales (e.g., communities) and population groups (e.g., based on age cohort, socioeconomic status, gender, identity, ethnicity) to understand and address societal challenges. One of the reasons why system dynamics models in relation to societal challenges were limited is that the complex feedback relationships involved in these societal issues, such as the strong causalities among economic depression, natural disasters, income inequality, epidemic diseases, poor education, and poverty, are so far much less understood or explored across scales. Despite this limited understanding, the influences of these societal challenges and their policy interventions on sustainable development are too significant to be ignored in system dynamics modelling. This signifies a need to improve the links between sustainability challenges (e.g., climate change, environmental footprints) and their related societal issues (e.g., poverty, inequality) as causes and consequences (88) in system dynamics models for the SDGs.

There are different ways for improving the links to societal factors in system dynamics models. First, the societal factors can be incorporated through exogenous scenarios $(89,90)$. The inclusion of societal factors as scenario drivers (e.g., in relation to gender, race, age, health) in models can help better capture inequalities (e.g., gender wage gap, mental health and well-being of people of different racial backgrounds) driven by external forces and assumptions. Some of these societal scenario drivers are known and are part of the climate and sustainability scenario frameworks (91). System dynamics applications need to parameterise and adopt them in their models.

Second, societal factors such as values, preferences, and distributional impacts can be endogenised in model structural components. An example is in differentiating between gender and age cohorts in school enrolment and graduation in a model structure to compute inequality in form of access to education across a population. Future studies can endogenise similar human factors through improving current societal assumptions in models via interdisciplinary learning and interaction with social sciences theories (92). A successful example of learning and interactions with other theories can be found in the transitions modelling field as a growing niche in computational social science for developing innovative models of co-evolution of behaviours and technologies (9). Modelling societal factors endogenously would also require further empirical research to understand and generalise common societal patterns important for modelling and integration with other modelling techniques (e.g., agent-based modelling) that can help in the (bottom-up) implementation human behaviour (92).

Third, societal factors can also be incorporated beyond individual components, and through the modelling of their feedback mechanisms with each other and with other biophysical systems. This facilitates a better understanding of the emergent behaviour of complex socio-ecological systems arising from the interactions of societal and sustainability challenges. For example, how a broader issue such as deforestation can result from the interaction of limited education as a key societal driver for diet change with high meat consumption and therefore faster destructive land-use change. Few previous system dynamics studies have shown examples of the modelling of human behaviour and its interactions with other sustainability issues such as diet shift (14) and climate change (93).

40 Future studies can further integrate the dynamics of societal factors in feedback interactions though learning from other areas that have tackled multisectoral dynamics, such as network analysis and modelling of interactions in complexity science (94) and integrated assessment (8).

The SDGs, as a guiding framework, can enhance the incorporation of societal factors through the ways mentioned above (i.e., scenarios, models, interactions) by providing a balanced

45 representation of sustainability dimensions. For example, Szetey et al. (34) recently used the SDGs 
to map a balanced representation of scenario drivers in a local community for a future system dynamics modelling work. Pedercini et al. (25) used SDGs as their analytical lens for endogenising societal aspects such as inequality and well-being in a system dynamics model. Randers et al. (16) also used the SDGs to understand the interactions and the entanglement of humanity and the biophysical environment to analyse environmental damage followed from socio-economic developments.

\subsection{Interdisciplinary approach}

A diversity of interdisciplinary methods was used to leverage the capabilities of system dynamics in the modelling of local sustainability. Past studies discussed some of the opportunities for integration (Section 3.2). Examples of integration were with discrete event simulation to incorporate process flow mapping features in system dynamics (95); with agent-based modelling to better capture actor behaviour and system heterogeneities (96); with fuzzy cognitive mapping to engage with stakeholders and use human opinion in the evaluation of causal relationships (97); with scenario analysis techniques to better account for alternative futures in modelling (98); with Bayesian networks to better manage missing data and uncertainty (99). Despite past efforts, integrations with new methods have not been necessarily guided to address the specific SDG characteristics, and therefore the opportunities and challenges of these SDG-motivated integrations have not been yet investigated or fully operationalised.

One of the specific characteristics in SDG analysis is the presence of deep uncertainties about the future (100) (e.g., technological breakthrough, political instability, ecological collapse) which can impact the validity of modelling assumptions and challenge the robustness of model results. To better address uncertainty, integration with new methods from other areas, such as robust decisionmaking (101) and exploratory modelling (102-104), has been suggested. Key to these new methods is the systematic generation and impact assessment of alternative plausible assumptions (i.e., many future projections which span the range of uncertainty across scenario, policy, model structure, and model parameter settings). Despite a few past studies integrating system dynamics with these methods at the national scale and in areas such as energy policy (105) and resource management (106), no such integration exists at the local scale and directly in relation to the SDGs. A recent synthesis of exploratory modelling (10) developed a typology of methods that can allow system dynamics models to explore future possibilities and their implications in the multidimensional output space of the SDGs. To illustrate, the design of experiments (106) can be used to randomly sample from the uncertainty assumptions in system dynamics models, generate an ensemble of model runs, and create an output space of projected futures with dimensions defined by the suite of sustainability indicators from the SDGs. Stress-testing and scenario discovery $(102,107)$ can be used to post-process the model runs and find crucial tipping points, scenario driver settings, and policy choices essential to meet SDGs, or conversely settings that result in failure. Multiobjective robust optimisation $(103,108)$ can be used to conduct new computational searches of the uncertainty and output spaces to identify robust, adaptive pathways that can manage synergies and trade-offs among SDGs in the face of future uncertainty. Available computational tools also exist $(104,109)$ which can support the implementation of these methods with system dynamics models as their simulation engine.

Another important SDG characteristic is the many interactions, such as trade-offs and synergies, which prevail between targets and between policy interventions affecting progress towards SDGs (110). Ignoring these interactions may risk reversing progress through the spillover effects of one goal's achievement at the cost of worsening several other goals. To make coherent policies and 
help policy-makers understand which goals and targets can be achieved together and which tradeoffs need be made, the SDG interactions need to at the centre of system dynamics model for sustainability. To identify synergies and trade-offs within and across SDGs for modelling, correlation analysis from statistics is a method that can provide a measure of how variables are related (39, 111). However, this data-driven analysis fails to address the key question of causal inference in SDG interactions, and needs to be supported with other complementary methods. Scoring-based approaches can be used to measure interaction intensity and direction based on the judgements of experts and stakeholders (112) to inform causal relationships for system dynamics modelling. Network analysis techniques can be used to explore more characteristics of interactions among SDGs: interaction strength, nature of interactions (such as interdependence, constraints, and reinforcement), and the 'nexus' relationship (113-115). In addition, interactive visual analytics (116118) can be used to facilitate stakeholder involvement and decision-making with the outcomes of system dynamics models by visualising co-achievement of multiple SDGs and associated policy pathways (110) as a result of trade-offs and synergies.

\subsection{Stakeholder participation}

System dynamics modelling was designed to be participatory from its inception, to involve stakeholders and decision-makers throughout various phases of modelling, and to benefit from this process in addition to the model as the final product (119). Stakeholder participation in system dynamics modelling, also known as group model building, ensures that the model combines scientific and local expert knowledge about a system (120). It aligns the mental models of stakeholders and creates a shared knowledge, understanding, and meaning (121). It is also shown to create consensus about both the causes and solutions of a problem, and to reduce conflict and build trust among the participating stakeholders $(122,123)$.

Despite the group model building tradition in system dynamics and increasing integration of modelling with genuine stakeholder engagement in sustainability research (36), more than $70 \%$ of the reviewed studies still did not have (or did not explicitly mention) engagement with stakeholders (Section 3.3). This transdisciplinary collaboration with stakeholders was limited across many of the SDGs (e.g., SDG6 on clean water and sanitation, SDG8 on decent work and economic growth). This gap can be justified in some cases in relation to the nature of the SDG goals and targets under study, for example when they were more related to the Earth and biophysical processes with limited human interaction and a stronger role for conventional disciplinary approaches. However, limited participation in respect of cultural, political, and societal goals and targets, which have a strong role for human interaction (e.g., transforming human lifestyle and consumption patterns in SDG12, improving governance arrangements in SDG16) can only indicate a gap and the need for further engagement with stakeholders in their modelling with system dynamics.

Future system dynamics studies in relation to the SDGs can address this gap by incorporating participatory activities in various modelling stages such as conceptualisation, review, and use (124126). In the conceptualisation stage, qualitative participatory approaches, e.g., systems mapping with causal loop diagrams, help not only to delineate problem boundaries and project scope, but also to enhance the policy-relevance of the eventual research findings, in addition to the abovementioned benefits such as shared understanding and trust building. In the review stage, participatory approaches enhance the perceived credibility and usefulness of the model among stakeholders (127). In the model use stage, participatory development and assessment of modelbased scenarios strengthen the understanding of system structures and resulting dynamic behaviour, why some policy options work or not, and how they can be improved, directly 
contributing to decision support. Interactive simulation environments $(128,129)$, which are enabled by the computational advantages of system dynamics modelling, are particularly useful in this stage since they provide the stakeholders with a first-hand experience of testing their own assumptions and policy options.

\subsection{Interaction analysis}

While previous system dynamics applications analysed issues related to multiple development goals together (Section 3.4), a specific focus on synergies and trade-offs as a key SDG feature and on common dynamic mechanisms which generate these interactions remained elusive. Structuring and evaluating these interactions and their underlying mechanisms upon which the SDGs operate are, however, crucial for understanding alternative ways that corporations (i.e., synergies) and conflicts (i.e., trade-offs) can emerge and designing coherent solutions which are structurally nonobstructive across the SDGs (130). For instance, strong interactions were identified between SDG11 (sustainable cities and communities) and several others (e.g., SDGs 6, 9,13, 15) (Section 3.4), which were related to the historical type of development, focusing on socio-economic growth regardless of the environmental and material footprint. Such interactions exemplify a generic tradeoff pattern that is not specific to these two goals and can equally occur across a multitude of systems varying in scope and goals. These recurring patterns, if understood correctly in relation to their underlying structures, can be reverted in the future with more effective policy agenda aimed at maximising the overall benefits across all SDGs.

Future research and practical decision-making can use available system dynamics tools, such as system archetypes (131), to specifically focus on SDG interactions and identify how synergies and trade-offs can emerge from underlying system structures and dynamic mechanisms. System archetypes as a category of systemic tools enable the shift from simple behavioural correlations to structural causality in the analysis of interactions where the aim is to identify generic explanations for classes of phenomena. To demonstrate how system archetypes can help with understanding causes and effects of a number of policy decisions related to the SDGs, we discuss three examples as an illustration (Figure 7).

Drifting Goals is one system archetype where two actions are possible to reduce the gap between current state and goal: either taking a corrective action which usually takes time, or simply lowering the goal ambition (Figure 7a). An example is provided from governments' goal of achieving certain carbon emissions reduction (SDG13) targets by 2030. In order to achieve this, a number of crucial policy decisions must be made, such as the transition to cleaner (e.g., renewables) forms of energy in contrast with fossil fuels (SDG7), both eventually creating balancing (or goal-seeking) feedback mechanisms towards reducing the emission target gap to zero. Such transition would likely take a long time to be completed, and in turn a significant delay can be expected before recording remarkable drops in emissions. At the same time, in the short-term, considerable disruption to the economy and the job market (SDG8) might arise, especially for states and regions heavily reliant on fossil fuels. Combining such impact on the economy and the lack of evident emissions reductions in the short-term, there might be pressure towards the government to reduce the emissions targets instead (e.g., lower emissions cut, longer timeframe). Here, a trade-off can clearly arise, between the need for climate action and transition to renewables (SDGs 7 and 13), and the goal of shortterm economic growth (SDG8). 


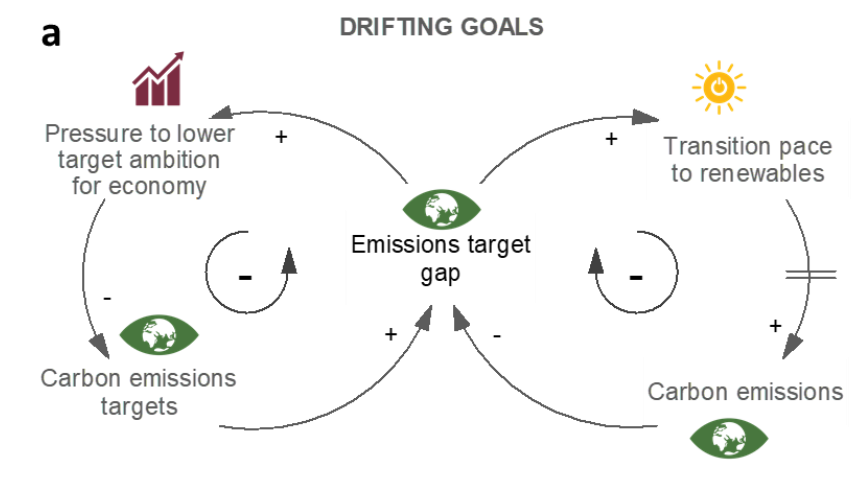

\section{c}

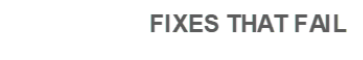

b

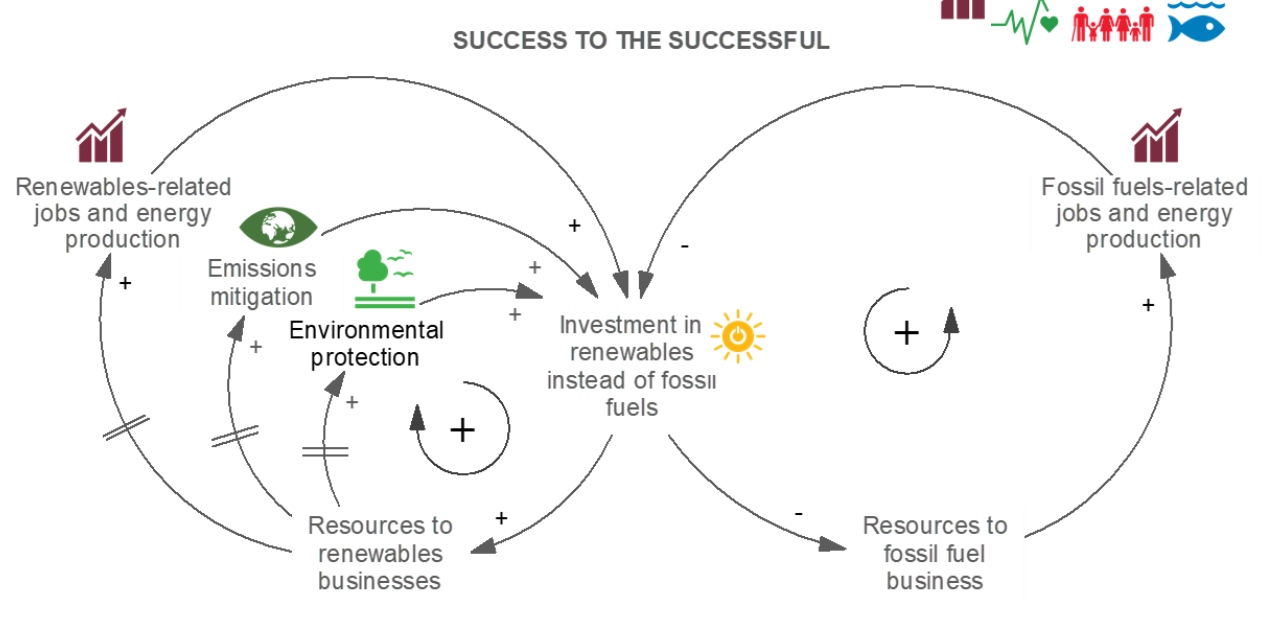

Figure 7. Three system archetypes to demonstrate examples of synergies and trade-offs between SDGs. (a) Drifting Goals, (b) Success to the Successful, and (c) Fixes that Fail. Arrows show interactions and the signs on arrows show the polarity of interaction (negative: trade-off; positive: synergy). The signed arrow loops indicate the feedback mechanisms where the positive sign represents a reinforcing loop (i.e., increase exponentially over time) and the negative sign represents a balancing loop (i.e., seek to achieve a goal). Relevant SDGs are identified next to each variable.

At the same time, the pace of transition to renewables, which relies on the investment in renewables instead of fossil fuels, can be also explained through another system archetype, called Success to the Successful (Figure 7b). In this archetype, the more success a certain sector/approach has had, the more resources are likely to be allocated to it in the future. This creates reinforcing feedback mechanisms, exponentially increasing the dominance of a sector or approach over time. In our example, the fossil fuel industry has received more resources and in turn delivered jobs, economic growth, and energy security in history. In this context, it is difficult for a niche and emerging system such as the renewable energy industry, as the most sustainable solution in the long run, to get attraction despite its apparent benefits. This is where the importance of a full system conceptualisation, beyond individual aspects, becomes evident: there are other variables to be included in the system, which might affect what we nowadays define as 'success', which is related to other SDGs (e.g., climate change mitigation, protection of environment and air quality), and will affect the final decision on resource allocation.

The complexity of the interconnection of factors within and across SDGs is more evident in the final example, which relies on the Fixes that Fail archetype where a short-term fix to an issue causes longer-term unintended consequences which may ultimately even aggravate the original problem (Figure 7c). Our example focuses on SDG2. While within SDG2, there is a focus both on zero hunger and sustainable agriculture, one region/community could address hunger and malnourishment by boosting agriculture with unstainable practices, which might look like the best solution for the short term and increase food production in a goal-seeking behaviour. However, 
several side effects can become apparent with reinforcing feedback mechanisms that can substantially deteriorate the situation over a longer time horizon. Among these side effects are: soil tilling, which can lead to unhealthy soil, malnourished plants, and in turn poor-quality food; soil erosion, which can cause drinking water contamination (SDG6) (132); unsustainable agriculture planning practices including deforestation, which causes loss of biodiversity (SDG15) and increasing risk of disease pandemics (SDG3); mono-cropping, which increases agricultural water demand (SDG6) (133) well as the need for chemicals and fertilisers, which can cause health issues (SDG3) and whose runoff can cause eutrophication (SDG6) and marine and aquatic ecosystem damage (SDG14). Over the long-term, such side effects will impact the country's economic growth (SDG8), potentially increasing poverty (SDG1), and ultimately leading to a long-term failure in addressing food security and food quality (SDG2).

More archetypes can be further identified and extracted from the proposed examples and from other SDG interactions. Given that previous studies (39) identified similar correlations (e.g., between SDGs 3 and 6) for several regions of the world, it is possible to backup such archetypes with historical data confirming or refining such conceptualisations. Overall, the goal for future research and practice should be to identify and better represent such common behaviours in relation to their underlying structural interactions, to move from simple association and correlations among SDGs to a full understanding of causes and effects in such complex systems. This will ultimately enable a better identification of effective strategies to maximise synergies and minimise trade-offs among SDGs.

\section{Conclusions}

The integrated analysis of sustainable development with its diverse goals and sectoral areas requires systemic approaches that can cope with and be extendable to various contexts, from wellbeing and social inclusion, to economic development, to environmental and ecological protection. Given the past methodological developments and the diversity of applications in relation to almost all sustainability areas, system dynamics is well placed to address some of the key challenges in the study of the SDGs. It can help in understanding the multisectoral dynamics behind SDG interactions and representing a diverse set of (i.e., societal, economic, environmental) sustainability indicators needed to measure the progress towards sustainable development. The diversity of analytical objectives and the extent of participatory research observed through the current review demonstrated this approach's flexibility to work under varying contextual conditions across applications. The wide range of interdisciplinary methods used in combination with system dynamics also showed opportunities for integration to overcome the limitations of this approach through the strengths of other supporting methods. This richness of models and their diverse applications reviewed in this article can provide an important knowledge base for further adoption and improvement of system dynamics studies with applications related to sustainability. Having said that, past studies were not complete in every aspect and had limitations to be addressed in the future. Researchers can cover some of these gaps by improving the links between societal factors and biophysical processes in sustainable development in models, engaging with a wider variety of 40 stakeholders during the modelling process, and understanding the underlying systematic structures that drive interactions among competing agendas based on archetypes.

\section{Acknowledgments}

This work is funded by The lan Potter Foundation and Deakin University. 


\section{Supplementary Materials}

Data S1. Collected articles from the literature search.

Data S2. Included articles in the review and their characterisation.

\section{Code and Data Availability}

The datasets (Data S1 and S2) generated during this study are available from https://doi.org/10.5281/zenodo.5094092. Further information and requests for resources and reagents should be directed to and will be fulfilled by the corresponding author.

\section{References}

$101 . \quad$ UN, "Transforming our world: the 2030 Agenda for Sustainable Development," Resolution adopted by the General Assembly on 25 September 2015 (The United Nations (UN), 2015).

2. J. D. Sachs, G. Schmidt-Traub, M. Mazzucato, D. Messner, N. Nakicenovic, J. Rockström, Six Transformations to achieve the Sustainable Development Goals. Nat. Sustain. 2, 805-814 (2019).

3. K. Neumann, C. Anderson, M. Denich, Participatory, explorative, qualitative modeling: application of the iMODELER software to assess trade-offs among the SDGs. Economics: The Open-Access, OpenAssessment E-Journal 25, 1-19 (2018).

4. T. Wiedmann, A review of recent multi-region input-output models used for consumption-based emission and resource accounting. Ecolog. Econ. 69, 211-222 (2009).

5. K. A. Babatunde, R. A. Begum, F. F. Said, Application of computable general equilibrium (CGE) to climate change mitigation policy: A systematic review. Renewable and Sustainable Energy Reviews 78, 61-71 (2017).

6. J. Sterman, T. Fiddaman, T. Franck, A. Jones, S. McCauley, P. Rice, E. Sawin, L. Siegel, Climate interactive: the C-ROADS climate policy model. System Dynamics Review 28, 295-305 (2012).

7. S. Greeven, O. Kraan, Chappin, Eacute, J. L. mile, J. H. Kwakkel, The Emergence of Climate Change Mitigation Action by Society: An Agent-Based Scenario Discovery Study. Journal of Artificial Societies and Social Simulation 19, 9 (2016).

8. L. van Beek, M. Hajer, P. Pelzer, D. van Vuuren, C. Cassen, Anticipating futures through models: the rise of Integrated Assessment Modelling in the climate science-policy interface since 1970. Global Environ. Change 65, 102191 (2020).

30 9. J. Köhler, F. de Haan, G. Holtz, K. Kubeczko, E. A. Moallemi, G. Papachristos, E. Chappin, Modelling Sustainability Transitions: An Assessment of Approaches and Challenges. Journal of Artificial Societies and Social Simulation 21, 8 (2018).

10. E. A. Moallemi, J. Kwakkel, F. de Haan, B. A. Bryan, Exploratory modeling for analyzing coupled human-natural systems under uncertainty. Global Environ. Change 102186, 102186 (2020).

35 11. S. Bankes, Exploratory modeling for policy analysis. Oper. Res. 41, 435-449 (1993).

12. J. D. Quinn, A. Hadjimichael, P. M. Reed, S. Steinschneider, Can Exploratory Modeling of Water Scarcity Vulnerabilities and Robustness Be Scenario Neutral? Earth's Future 8, e2020EF001650 (2020)

13. P. H. Verburg, J. A. Dearing, J. G. Dyke, S. v. d. Leeuw, S. Seitzinger, W. Steffen, J. Syvitski, Methods and approaches to modelling the Anthropocene. Global Environ. Change 39, 328-340 (2016).

14. S. Eker, G. Reese, M. Obersteiner, Modelling the drivers of a widespread shift to sustainable diets. Nat. Sustain., (2019). 
15. B. Walsh, P. Ciais, I. A. Janssens, J. Peñuelas, K. Riahi, F. Rydzak, D. P. van Vuuren, M. Obersteiner, Pathways for balancing CO2 emissions and sinks. Nat. Commun. 8, 14856 (2017).

16. J. Randers, J. Rockström, P.-E. Stoknes, U. Goluke, D. Collste, S. E. Cornell, J. Donges, Achieving the 17 Sustainable Development Goals within 9 planetary boundaries. Global Sustainability 2, e24 (2019).

17. C. Allen, G. Metternicht, T. Wiedmann, M. Pedercini, Greater gains for Australia by tackling all SDGs but the last steps will be the most challenging. Nat. Sustain. 2, 1041-1050 (2019).

18. M. Pedercini, S. Arquitt, D. Chan, Integrated simulation for the 2030 agendat. System Dynamics Review 36, 333-357 (2020).

19. J. Forrester, World Dynamics. (Wright-Allen Press, Cambridge, Massachusetts, 1971).

10 20. D. H. Meadows, D. L. Meadows, J. Randers, W. W. Behrens, The limits to growth. New York 102, 27 (1972).

21. A. Ford, System dynamics and the electric power industry. System Dynamics Review: The Journal of the System Dynamics Society 13, 57-85 (1997).

22. T. S. Fiddaman, Exploring policy options with a behavioral climate-economy model. System Dynamics Review: The Journal of the System Dynamics Society 18, 243-267 (2002).

23. C. Holz, L. S. Siegel, E. Johnston, A. P. Jones, J. Sterman, Ratcheting ambition to limit warming to $1.5^{\circ} \mathrm{C}$-trade-offs between emission reductions and carbon dioxide removal. Environmental Research Letters 13, 064028 (2018).

24. K. Saeed, Towards sustainable development: Essays on system analysis of national policy. (Routledge, London, 1991).

25. M. Pedercini, S. Arquitt, D. Collste, H. Herren, Harvesting synergy from sustainable development goal interactions. PNAS 116, 23021 (2019).

26. Z. Ravar, B. Zahraie, A. Sharifinejad, H. Gozini, S. Jafari, System dynamics modeling for assessment of water-food-energy resources security and nexus in Gavkhuni basin in Iran. Ecol. Indic. 108, 105682 (2020).

27. J. D. Sterman, System Dynamics Modeling: Tools for Learning in a Complex World. Calif. Manage. Rev. 43, 8-25 (2001).

28. J. W. Forrester, System dynamics-a personal view of the first fifty years. System Dynamics Review 23, 345-358 (2007).

29. S. P. Shepherd, A review of system dynamics models applied in transportation. Transportmetrica $B$ : Transport Dynamics 2, 83-105 (2014).

30. B. J. Angerhofer, M. C. Angelides, in 2000 Winter Simulation Conference Proceedings (Cat. No.00CH37165). (2000), vol. 1, pp. 342-351 vol.341.

31. T. D. Phan, E. Bertone, R. A. Stewart, Critical review of system dynamics modelling applications for water resources planning and management. Cleaner Environmental Systems 2, 100031 (2021).

32. P. Messerli, E. M. Kim, W. Lutz, J.-P. Moatti, K. Richardson, M. Saidam, D. Smith, P. EloundouEnyegue, E. Foli, A. Glassman, G. H. Licona, E. Murniningtyas, J. K. Staniškis, J.-P. van Ypersele, E. Furman, Expansion of sustainability science needed for the SDGs. Nat. Sustain. 2, 892-894 (2019).

33. E. A. Moallemi, S. Malekpour, M. Hadjikakou, R. Raven, K. Szetey, D. Ningrum, A. Dhiaulhaq, B. A. Bryan, Achieving the Sustainable Development Goals requires transdisciplinary innovation at the local scale. One Earth 3, 300-313 (2020). 
34. K. Szetey, E. A. Moallemi, E. Ashton, M. Butcher, B. Sprunt, B. A. Bryan, Co-creating local socioeconomic pathways for achieving the sustainable development goals. Sustainability Science, (2021).

35. D. Moher, A. Liberati, J. Tetzlaff, D. G. Altman, Preferred reporting items for systematic reviews and meta-analyses: the PRISMA statement. BMJ 339, b2535 (2009).

36. A. Voinov, K. Jenni, S. Gray, N. Kolagani, P. D. Glynn, P. Bommel, C. Prell, M. Zellner, M. Paolisso, R. Jordan, E. Sterling, L. Schmitt Olabisi, P. J. Giabbanelli, Z. Sun, C. Le Page, S. Elsawah, T. K. BenDor, K. Hubacek, B. K. Laursen, A. Jetter, L. Basco-Carrera, A. Singer, L. Young, J. Brunacini, A. Smajgl, Tools and methods in participatory modeling: Selecting the right tool for the job. Environ. Model. Software 109, 232-255 (2018).

37. E. A. Moallemi, F. J. de Haan, M. Hadjikakou, S. Khatami, S. Malekpour, A. Smajgl, M. Stafford Smith, A. Voinov, R. Bandari, P. Lamichhane, K. K. Miller, E. Nicholson, W. Novalia, E. G. Ritchie, A. M. Rojas, M. A. Shaikh, K. Szetey, B. A. Bryan, Evaluating participatory modelling methods for co-creating pathways to sustainability. Earth's Future, (2021).

38. A. V. Norström, C. Cvitanovic, M. F. Löf, S. West, C. Wyborn, P. Balvanera, A. T. Bednarek, E. M. Bennett, R. Biggs, A. de Bremond, B. M. Campbell, J. G. Canadell, S. R. Carpenter, C. Folke, E. A. Fulton, O. Gaffney, S. Gelcich, J.-B. Jouffray, M. Leach, M. Le Tissier, B. Martín-López, E. Louder, M.F. Loutre, A. M. Meadow, H. Nagendra, D. Payne, G. D. Peterson, B. Reyers, R. Scholes, C. I. Speranza, M. Spierenburg, M. Stafford-Smith, M. Tengö, S. van der Hel, I. van Putten, H. Österblom, Principles for knowledge co-production in sustainability research. Nat. Sustain., (2020).

39. P. Pradhan, L. Costa, D. Rybski, W. Lucht, J. P. Kropp, A Systematic Study of Sustainable Development Goal (SDG) Interactions. Earth's Future 5, 1169-1179 (2017).

40. M. H. Ahmadi, M. Zarghami, Should water supply for megacities depend on outside resources? A Monte-Carlo system dynamics simulation for Shiraz, Iran. Sustainable Cities and Society 44, 163-170 (2019).

41. C. Prouty, S. Mohebbi, Q. Zhang, Socio-technical strategies and behavior change to increase the adoption and sustainability of wastewater resource recovery systems. Water Res. 137, 107-119 (2018).

42. A. Bagheri, F. Babaeian, Assessing water security of Rafsanjan Plain, Iran - Adopting the SEEA framework of water accounting. Ecol. Indic. 111, (2020).

43. W. P. Tsai, C. L. Cheng, T. S. Uen, Y. Zhou, F. J. Chang, Drought mitigation under urbanization through an intelligent water allocation system. Agric. Water Manage. 213, 87-96 (2019).

44. Y. H. Cheng, Y. H. Chang, I. J. Lu, Urban transportation energy and carbon dioxide emission reduction strategies. Applied Energy 157, 953-973 (2015).

45. M. C. P. Sing, P. E. D. Love, H. J. Liu, Rehabilitation of existing building stock: A system dynamics model to support policy development. Cities 87, 142-152 (2019).

46. N. Tsolakis, L. Anthopoulos, Eco-cities: An integrated system dynamics framework and a concise research taxonomy. Sustainable Cities and Society 17, 1-14 (2015).

47. L. L. Guo, Y. Qu, C. Y. Wu, X. L. Wang, Identifying a pathway towards green growth of Chinese industrial regions based on a system dynamics approach. Resources, Conservation and Recycling 128, 143-154 (2018).

48. A. Perrone, A. Inam, R. Albano, J. Adamowski, A. Sole, A participatory system dynamics modeling approach to facilitate collaborative flood risk management: A case study in the Bradano River (Italy). J. Hydrol 580, (2020).

49. A. C. Cagliano, A. Carlin, G. Mangano, C. Rafele, Analyzing the diffusion of eco-friendly vans for urban freight distribution. International Journal of Logistics Management 28, 1218-1242 (2017). 
50. F. Meinherz, N. Videira, Integrating Qualitative and Quantitative Methods in Participatory Modeling to Elicit Behavioral Drivers in Environmental Dilemmas: the Case of Air Pollution in Talca, Chile. Environ. Manage. 62, 260-276 (2018).

51. G. Mangano, G. Zenezini, A. C. Cagliano, A. De Marco, The dynamics of diffusion of an electronic platform supporting City Logistics services. Operations Management Research 12, 182-198 (2019).

52. T. S. Bixler, J. Houle, T. Ballestero, W. Mo, A dynamic life cycle assessment of green infrastructures. Sci. Total Environ. 692, 1146-1154 (2019).

53. L. Wan, Y. Zhang, S. Qi, H. Li, X. Chen, S. Zang, A study of regional sustainable development based on GIS/RS and SD model - Case of Hadaqi industrial corridor. Journal of Cleaner Production 142, 654-662 (2017).

54. C. Fang, X. Cui, G. Li, C. Bao, Z. Wang, H. Ma, S. Sun, H. Liu, K. Luo, Y. Ren, Modeling regional sustainable development scenarios using the Urbanization and Eco-environment Coupler: Case study of Beijing-Tianjin-Hebei urban agglomeration, China. Sci. Total Environ. 689, 820-830 (2019).

55. K. Karimlou, N. Hassani, A. Rashidi Mehrabadi, M. R. Nazari, Developing a Model for Decision-Makers in Dynamic Modeling of Urban Water System Management. Water Resour. Manage. 34, 481-499 (2020).

56. T. F. Luna, M. Uriona-Maldonado, M. E. Silva, C. R. Vaz, The influence of e-carsharing schemes on electric vehicle adoption and carbon emissions: An emerging economy study. Transportation Research Part D: Transport and Environment 79, (2020).

57. UN DESA, "World Urbanization Prospects 2018," (2018).

58. D. Liu, X. Zheng, H. Wang, Land-use Simulation and Decision-Support system (LandSDS): Seamlessly integrating system dynamics, agent-based model, and cellular automata. Ecol. Modell. 417, (2020).

59. A. Tenza, J. Martínez-Fernández, I. Pérez-Ibarra, A. Giménez, Sustainability of small-scale socialecological systems in arid environments: trade-off and synergies of global and regional changes. Sustainability Science 14, 791-807 (2019).

60. M. Pejic Bach, E. Tustanovski, A. W. H. Ip, K. L. Yung, V. Roblek, System dynamics models for the simulation of sustainable urban development: A review and analysis and the stakeholder perspective. Kybernetes 49, 460-504 (2019).

61. T. Beaussier, S. Caurla, V. Bellon-Maurel, E. Loiseau, Coupling economic models and environmental assessment methods to support regional policies: A critical review. Journal of Cleaner Production 216, 408-421 (2019).

62. Y. Rusuli, L. Li, S. Ahmad, X. Zhao, Dynamics model to simulate water and salt balance of Bosten Lake in Xinjiang, China. Environmental Earth Sciences 74, 2499-2510 (2015).

63. G. Chhipi-Shrestha, K. Hewage, R. Sadiq, Water-energy-carbon nexus modeling for urban water systems: System dynamics approach. Journal of Water Resources Planning and Management 143, (2017).

64. J. P. Walters, A. N. Javernick-Will, Long-term functionality of rural water services in developing countries: A system dynamics approach to understanding the dynamic interaction of factors. Environmental Science and Technology 49, 5035-5043 (2015).

$40 \quad 65 . \quad$ T. Han, C. Zhang, Y. Sun, X. Hu, Study on environment-economy-society relationship model of Liaohe River Basin based on multi-agent simulation. Ecol. Modell. 359, 135-145 (2017).

66. Q. Su, H. Dai, Y. Lin, H. Chen, R. Karthikeyan, Modeling the carbon-energy-water nexus in a rapidly urbanizing catchment: A general equilibrium assessment. J. Environ. Manage. 225, 93-103 (2018).

67. E. Bertone, O. Sahin, R. A. Stewart, P. X. W. Zou, M. Alam, K. Hampson, E. Blair, Role of financial mechanisms for accelerating the rate of water and energy efficiency retrofits in Australian public 
buildings: Hybrid Bayesian Network and System Dynamics modelling approach. Applied Energy 210, 409-419 (2018).

68. L. Cox, A. Bassi, J. Kolling, A. Procter, N. Flanders, N. Tanners, R. Araujo, Exploring synergies between transit investment and dense redevelopment: A scenario analysis in a rapidly urbanizing landscape. Landscape Urban Plann. 167, 429-440 (2017).

69. S. H. Sadeghi, E. Sharifi Moghadam, M. Delavar, M. Zarghami, Application of water-energy-food nexus approach for designating optimal agricultural management pattern at a watershed scale. Agric. Water Manage. 233, (2020).

70. C. Kelly, B. Sen, O. Tatari, A system dynamics analysis of the alternative roofing market and its potential impacts on urban environmental problems: A case study in Orlando, Florida. Resources, Conservation and Recycling 153, (2020).

71. A. Tenza, I. Pérez, J. Martínez-Fernández, A. Giménez, Understanding the decline and resilience loss of a long-lived socialecological system: Insights from system dynamics. Ecol. Soc. 22, (2017).

72. B. Cavicchi, Sustainability that backfires: the case of biogas in Emilia Romagna. Environmental Innovation and Societal Transitions 21, 13-27 (2016).

73. M. R. Weeks, D. W. Lounsbury, J. Li, G. Hirsch, M. Berman, H. D. Green, L. Rohena, R. Gonzalez, J. M. Montezuma-Rusca, S. Jackson, Simulating system dynamics of the HIV care continuum to achieve treatment as prevention. PLoS One 15, (2020).

74. B. Cavicchi, The burden of sustainability: Limits to sustainable bioenergy development in Norway.

75. F. Zare, S. Elsawah, A. Bagheri, E. Nabavi, A. J. Jakeman, Improved integrated water resource modelling by combining DPSIR and system dynamics conceptual modelling techniques. J. Environ. Manage. 246, 27-41 (2019).

76. A. Macmillan, M. Smith, K. Witten, A. Woodward, J. Hosking, K. Wild, A. Field, Suburb-level changes for active transport to meet the SDGs: Causal theory and a New Zealand case study. Sci. Total Environ. 714, (2020).

77. A. Ghasemi, B. Saghafian, S. Golian, System dynamics approach for simulating water resources of an urban water system with emphasis on sustainability of groundwater. Environmental Earth Sciences 76, (2017).

78. T. Wei, I. Lou, Z. Yang, Y. Li, A system dynamics urban water management model for Macau, China. J. Environ. Sci. (China) 50, 117-126 (2016).

79. S. Yin, G. Dongjie, S. Weici, G. Weijun, Integrated assessment and scenarios simulation of urban water security system in the southwest of China with system dynamics analysis. Water Sci. Technol. 76, 22552267 (2017).

80. Y. Zhou, H. Liu, J. Zhou, M. Xia, Simulation of the impact of urban forest scale on PM2.5 and PM10 based on system dynamic. Sustainability (Switzerland) 11, (2019).

81. Y. Teng, W. Xia, Research on system dynamics of urban land comprehensive carrying capacity in Xi'an City, China. Open Cybernetics and Systemics Journal 9, 1929-1936 (2015).

82. C. Wang, Y. Hou, Y. Xue, Water resources carrying capacity of wetlands in Beijing: Analysis of policy optimization for urban wetland water resources management. Journal of Cleaner Production 161, 11801191 (2017).

83. W. J. Tan, C. F. Yang, P. A. Château, M. T. Lee, Y. C. Chang, Integrated coastal-zone management for sustainable tourism using a decision support system based on system dynamics: A case study of Cijin, Kaohsiung, Taiwan. Ocean and Coastal Management 153, 131-139 (2018). 
84. Widhianthini, A dynamic model for sustainable tourism village planning based on local institutions. Journal of Regional and City Planning 28, 1-15 (2017).

85. S. O. Inomata, A. M. G. O. Gonzalez, R. M. S. Román, L. A. de Souza, C. E. de Carvalho Freitas, Sustainability of small-scale fisheries in the middle Negro River (Amazonas - Brazil): A model with operational and biological variables. Ecol. Modell. 368, 312-320 (2018).

86. F. R. A. Nascimento, A. Kiperstok, J. Martín, J. Morató, E. Cohim, Decision support system for management of reactive nitrogen flows in wastewater system. Environmental Science and Pollution Research 25, 8644-8653 (2018).

87. S. Rostami, Interactive Chord Diagram. (2021).

88. B. A. Jafino, J. H. Kwakkel, B. Taebi, Enabling assessment of distributive justice through models for climate change planning: A review of recent advances and a research agenda. WIREs Climate Change n/a, e721 (2021).

89. J. Emmerling, M. Tavoni, Representing inequalities in integrated assessment modeling of climate change. One Earth 4, 177-180 (2021).

90. K. Ilkka, B. Isabela, B. Nicolas, C. Matteo, E. Oreane, E. Johannes, F. Panagiotis, G. Celine, H. Mathijs, L. Julien, G. Thomas Le, L. Marian, M. Will, M. Jean-Francois, S. Roberto, T. Evelina, W. Fabian, Exploring the possibility space: Taking stock of the diverse capabilities and gaps in integrated assessment models. Environmental Research Letters, (2021).

91. B. C. O'Neill, T. R. Carter, K. Ebi, P. A. Harrison, E. Kemp-Benedict, K. Kok, E. Kriegler, B. L. Preston, K. Riahi, J. Sillmann, B. J. van Ruijven, D. van Vuuren, D. Carlisle, C. Conde, J. Fuglestvedt, C. Green, T. Hasegawa, J. Leininger, S. Monteith, R. Pichs-Madruga, Achievements and needs for the climate change scenario framework. Nat. Clim. Change. 10, 1074-1084 (2020).

92. E. Trutnevyte, L. F. Hirt, N. Bauer, A. Cherp, A. Hawkes, O. Y. Edelenbosch, S. Pedde, D. P. van Vuuren, Societal Transformations in Models for Energy and Climate Policy: The Ambitious Next Step. One Earth 1, 423-433 (2019).

93. B. Beckage, L. J. Gross, K. Lacasse, E. Carr, S. S. Metcalf, J. M. Winter, P. D. Howe, N. Fefferman, T. Franck, A. Zia, A. Kinzig, F. M. Hoffman, Linking models of human behaviour and climate alters projected climate change. Nat. Clim. Change. 8, 79-84 (2018).

94. B. Edmonds, Complexity and Scientific Modelling. Foundations of Science 5, 379-390 (2000).

95. J. S. Morgan, S. Howick, V. Belton, A toolkit of designs for mixing Discrete Event Simulation and System Dynamics. European Journal of Operational Research 257, 907-918 (2017).

96. E. Shafiei, H. Stefansson, E. I. Asgeirsson, B. Davidsdottir, M. Raberto, Integrated agent-based and system dynamics modelling for simulation of sustainable mobility. Transport Reviews 33, 44-70 (2013).

97. J. P. C. Fonseca, F. A. F. Ferreira, L. F. Pereira, K. Govindan, I. Meidutè-Kavaliauskienè, Analyzing determinants of environmental conduct in small and medium-sized enterprises: A sociotechnical approach. Journal of Cleaner Production 256, (2020).

98. C. Godde, K. Dizyee, A. Ash, P. Thornton, L. Sloat, E. Roura, B. Henderson, M. Herrero, Climate change and variability impacts on grazing herds: Insights from a system dynamics approach for semiarid Australian rangelands. Glob. Chang. Biol. 25, 3091-3109 (2019).

99. E. Bertone, O. Sahin, R. Richards, A. Roiko, Assessing the impacts of extreme weather events on potable water quality: the value to managers of a highly participatory, integrated modelling approach. H2Open Journal 2, 9-24 (2018).

100. W. E. Walker, R. J. Lempert, J. Kwakkel, in Encyclopedia of Operations Research and Management Science, S. I. Gass, M. C. Fu, Eds. (Springer, New York, 2013). 
101. V. A. W. J. Marchau, W. E. Walker, P. J. T. M. Bloemen, S. W. Popper, Decision Making under Deep Uncertainty: From Theory to Practice. (Springer, New York, 2019).

102. A. Hadjimichael, J. Quinn, E. Wilson, P. Reed, L. Basdekas, D. Yates, M. Garrison, Defining robustness, vulnerabilities, and consequential scenarios for diverse stakeholder interests in institutionally complex river basins. Earth's Future n/a, e2020EF001503 (2020).

103. D. F. Gold, P. M. Reed, B. C. Trindade, G. W. Characklis, Identifying Actionable Compromises: Navigating Multi-City Robustness Conflicts to Discover Cooperative Safe Operating Spaces for Regional Water Supply Portfolios. Water Resources Res. n/a, (2019).

104. J. H. Kwakkel, The Exploratory Modeling Workbench: An open source toolkit for exploratory modeling, scenario discovery, and (multi-objective) robust decision making. Environ. Model. Software 96, 239250 (2017).

105. S. Eker, E. van Daalen, A model-based analysis of biomethane production in the Netherlands and the effectiveness of the subsidization policy under uncertainty. Energy Policy 82, 178-196 (2015).

106. J. H. Kwakkel, E. Pruyt, Exploratory Modeling and Analysis, an approach for model-based foresight under deep uncertainty. Technol. Forecast. Soc. Change 80, 419-431 (2013).

107. J. R. Lamontagne, P. M. Reed, R. Link, K. V. Calvin, L. E. Clarke, J. A. Edmonds, Large Ensemble Analytic Framework for Consequence-Driven Discovery of Climate Change Scenarios. Earth's Future 6, 488-504 (2018).

108. R. Singh, P. M. Reed, K. Keller, Many-objective robust decision making for managing an ecosystem with a deeply uncertain threshold response. Ecology and Society 20, 12 (2015).

109. A. Hadjimichael, D. Gold, D. Hadka, P. Reed, Rhodium: Python Library for Many-Objective Robust Decision Making and Exploratory Modeling. Journal of Open Research Software 8, 12 (2020).

110. L. Gao, B. A. Bryan, Finding pathways to national-scale land-sector sustainability. Nature 544, 217 (2017).

111. A. Warchold, P. Pradhan, J. P. Kropp, Variations in sustainable development goal interactions: Population, regional, and income disaggregation. Sustainable Development 29, 285-299 (2021).

112. M. Nilsson, D. Griggs, M. Visbeck, Policy: map the interactions between Sustainable Development Goals. Nature 534, 320-322 (2016).

113. A. Jiménez-Aceituno, G. D. Peterson, A. V. Norström, G. Y. Wong, A. S. Downing, Local lens for SDG implementation: lessons from bottom-up approaches in Africa. Sustainability Science 15, 729-743 (2020).

114. D. Le Blanc, Towards Integration at Last? The Sustainable Development Goals as a Network of Targets. Sustainable Development 23, 176-187 (2015).

115. N. Weitz, M. Nilsson, M. Davis, A Nexus Approach to the Post-2015 Agenda: Formulating Integrated Water, Energy, and Food SDGs. SAIS Review of International Affairs 34, 37-50 (2014).

116. J. R. Kasprzyk, S. Nataraj, P. M. Reed, R. J. Lempert, Many objective robust decision making for complex environmental systems undergoing change. Environ. Model. Software 42, 55-71 (2013).

117. P. M. Reed, J. B. Kollat, Visual analytics clarify the scalability and effectiveness of massively parallel many-objective optimization: A groundwater monitoring design example. Advances in Water Resources 56, 1-13 (2013).

118. E. A. Moallemi, F. Zare, P. M. Reed, S. Elsawah, M. J. Ryan, B. A. Bryan, Structuring and evaluating decision support processes to enhance the robustness of complex human-natural systems. Environ. Model. Software 123, 1045-1051 (2020).

119. J. W. Forrester, "The" model versus a modeling "process". System Dynamics Review 1, 133-134 (1985). 
120. D. F. Andersen, J. A. M. Vennix, G. P. Richardson, E. A. J. A. Rouwette, Group model building: problem structuring, policy simulation and decision support. J. Oper. Res. Soc. 58, 691-694 (2007).

121. N. Zimmermann, The Contribution of Theory and Experience to Generic Meaning-making: A Reflection on Participatory System Dynamics Modelling. Systems Research and Behavioral Science 34, 489-493 (2017).

122. K. Stave, Participatory System Dynamics Modeling for Sustainable Environmental Management: Observations from Four Cases. Sustainability 2, (2010).

123. E. A. J. A. Rouwette, J. A. M. Vennix, T. v. Mullekom, Group model building effectiveness: a review of assessment studies. System Dynamics Review 18, 5-45 (2002).

124. J. Halbe, G. Holtz, S. Ruutu, Participatory modeling for transition governance: Linking methods to process phases. Environmental Innovation and Societal Transitions 35, 60-76 (2020).

125. E. Bertone, O. Sahin, R. Richards, A. Roiko, in International Congress on Environmental Modelling and Software. (Toulouse, France, 2016), vol. 66.

126. P. Aminpour, S. A. Gray, A. J. Jetter, J. E. Introne, A. Singer, R. Arlinghaus, Wisdom of stakeholder crowds in complex social-ecological systems. Nat. Sustain. 3, 191-199 (2020).

127. S. Eker, E. Rovenskaya, M. Obersteiner, S. Langan, Practice and perspectives in the validation of resource management models. Nat. Commun. 9, 5359 (2018).

128. J. D. Sterman, T. Fiddaman, T. Franck, A. Jones, S. McCauley, P. Rice, E. Sawin, L. Siegel, Management flight simulators to support climate negotiations. Environ. Model. Software 44, 122-135 (2013).

129. S. Eker, N. Zimmermann, S. Carnohan, M. Davies, Participatory system dynamics modelling for housing, energy and wellbeing interactions. Build. Res. Inf. 46, 738-754 (2018).

130. D. Collste, M. Pedercini, S. E. Cornell, Policy coherence to achieve the SDGs: using integrated simulation models to assess effective policies. Sustainability Science 12, 921-931 (2017).

131. E. Wolstenholme, Using generic system archetypes to support thinking and modelling. System Dynamics Review: The Journal of the System Dynamics Society 20, 341-356 (2004).

132. S. Keesstra, P. Pereira, A. Novara, E. C. Brevik, C. Azorin-Molina, L. Parras-Alcántara, A. Jordán, A. Cerdà, Effects of soil management techniques on soil water erosion in apricot orchards. Sci. Total Environ. 551-552, 357-366 (2016).

30 133. D. F. Levia, I. F. Creed, D. M. Hannah, K. Nanko, E. W. Boyer, D. E. Carlyle-Moses, N. van de Giesen, D. Grasso, A. J. Guswa, J. E. Hudson, S. A. Hudson, S. i. lida, R. B. Jackson, G. G. Katul, T. o. Kumagai, P. Llorens, F. L. Ribeiro, D. E. Pataki, C. A. Peters, D. S. Carretero, J. S. Selker, D. Tetzlaff, M. Zalewski, M. Bruen, Homogenization of the terrestrial water cycle. Nat. Geosci. 13, 656-658 (2020). 